MIECZYSŁAW WRZOSEK (Warszawa)

\title{
DOKUMENTY DOTYCZĄCE POLITYCZNYCH ZMAGAŃ JÓZEFA PIŁSUDSKIEGO I SPRAWY POLSKIEJ PODCZAS PIERWSZEJ WOJNY ŚWIATOWEJ (SIERPIEŃ - PAŹDZIERNIK 1916)
}

\author{
CZĘŚĆ II ${ }^{1}$
}

\section{Dokument nr 1}

1916 sierpień 31, Cieszyn. - Pismo szefa Sztabu Generalnego armii austro-wegierskiej generata Franza Conrada con Hötzendorfa do austro-węgierskiego ministra spraw zagranicznych barona Stefana Buriana von Rajecz w sprawie przemianowania Legionów Polskich na Polski Korpus Positkowy. Nota $n r 18254$.

Eure Excellenz beehre ich mich beiliegend eine Kopie der an den Vorstand der Militärkanzlei Seiner Majestät gerichteten Zuschrift betreffens Ausgestaltung der Polnischen Legion zu einem „Polnischen Hilfskorps” zur geöffentliche Kentnis zu iibermitteln.

Diese Massnahme betrachtet das AOK sowohl als eine im Militärischen Interesse gelegen Vorbereitung für die eventuelle Schaffung einer polnischen Armee, wie auch als ein besonderes Entgegenkommen gegenüber den polnischen Wïnschen und als eine Vorstufe zu der den Polen zugedachten staatlichen Selbstständigkeit.

1 Niniejsza publikacja obejmuje druga część dokumentów opublikowanych w: „Studia Podlaskie", tom X, Białystok 2000, s. 281-337. 
Bei diesem Anlasse beehre ich mich, an Euer Exzellenz das Ersuchen zu richten, da AOK über den dermaligen Stand unserer Verhandlungen mit der deutschen Regierung in der Polenfrage, insbesonders darüber orientieren zu wollen, ob und wann etwa die beabsichtigte Deklaration Polens als selbstständindiges Königreich gewärtigt werden kann.

Euer Exzellenz worden gewiss mit mir dahin iibeeinstimmen, dass nunmehr - nach dem Eintritt Rumäniens in der Krieg:

1) jene Griinde hinfällig sind, welche von deutscher Seite für einen Aufschub der Deklaration in der polnischen Frage geltend gemacht wurden und,

2) das Bedürfnis, unsere Streitkräfte durch Schaffung der polnischen Armee zu vestärken, niemals dringender war als jetzt.

Zögerdner Aufschub wird in unserer Lage zum schweren Versäumnis.

Franz Conrad von Hötzendorf

Oryginał, maszynopis.

Haus - Hof - und Staatsarchiv, Krieg, PA I, karton 901, plik Polnische Legionen, folium (numer karty w pliku akt) 6.

\section{Dokument nr 2}

1916 sierpień 31, Wiedeń. - Pismo austro-wegierskiej Naczelnej Komendy Armii do szefa Wojskowej Kancelarii przy cesarzu Austrii barona Artura von Bolfrasa w sprawie reorganizacji Legionów Polskich.

Das zur Neige gehende Menschenmaterial der Monarchie zwingt das AOK angesichts der sich stetig mehrenden Zahl unserer Feinde und des ihnen zu Gebote stehenden unerschöpflichen Menschensreservoirs jede sich bietende Hilfsquelle für die interessen der Monarchie auszuwerten und neue Quellen zu erschliessen.

Unter den bezüglichen Massnahmen wird zunächst die Reorganisation der Polnischen Legionen ins Auge gefasst.

Diese seit 2 Jahren im Verbande der k.u.k. Armee kämfende, vielfach bewährte Freiwilligenformation ist in den letzten Zeit infolge grosser Verluste zu einem chwachen Kader zusammengeschmolzen. Wegen des Mangels einer bestimmten Zusage über die politische Zukunft Russisch - Polens seitens der Zentralmächte und dadurch herrschenden Unklarheit ergibt die 
Werbung für die Polnischen Legionen von Tag zu Tag schwächere Resultate. Das AOK ist demnach im militärischen Interesse genötigt, die Grundlage und Organisation der Legionen zu ändern und beabsichtigt gleichzeitig, einen weiteren Ausbau vorzunehmen, um den nationalen Aspirationen der Polen entgegenzukommen.

Das AOK hat hiezu nach reiflicher Ewägung Folgendes in Aussicht genommen:

1) Bewilligung für die bei den Polnischen Legionen eingeteilten k.u.k. Offiziere zumTrugen der Legionsuniform.

Diese Offiziere wïrden von nun an als in der k.u.k. Armee „ïberkomplett" zur polnischen Legion abkommandiert zu führen sein; im Übrigen würden ihnen aber alle Rechte und Pflichten der ku.k. Offiziere nach wie vor zukommen.

Welche Legionsoffizierscharge diesen Offizieren auf Kriegsdauer zu verleihen wäre, wïrde das $\mathrm{AOK}$ in jedem einzelnen Falle, je nach bisheriger Dauer der Offiziersdienstzeit, bestimmen.

2) Verleihun von Fahnen an die Legionsinfanterieregimenter und zwar der historischen polnischen Fahnen - auf der einen Seite mit dem polnischen Adler, auf der anderen mit dem Bildnis der Heiligen Mutter Gottes.

3) Ausgestaltung der Polnischen Legionen in 2 komplette Infanteriedivisionen á 12 Baone mit der zugehörigen Artillerie und den entsprechenden Anstalten und Neubenennung der gesammten in Russisch - Polen aufgestellten Truppen als „Polnisches Hilfskorps”, wobei jedoch diese Bezeichnung nicht als die eines „Armeekorps" aufzufassen ist.

Die beiden Divisionen wïrden die Benennung „1. Und 2. Polnische Legion" führen; bei einer eventuellen vorïbergehenden Verenigung beider Divisionen würde der ältere der beiden Divisionen das Kommando übernehmen, da die Neuaufstellung eines Korpsstabes unter keinen Uständen geplant ist.

Die drei vorgenannten Organisationsänderungrn stellen Wïnsche des Obersten Polnischen Nationalkomitees und der polnischen Legionen dar.

Das AOK erwartet von deren Erfüllung eine Belebung des allgemeinen Interesses für die Polnischen Legionen in Russisch - polen und einen regeren Zufluss zur Werbung. Insbesondere wird die Bezeichnung „Polnisches Hilfkorps" als Schlagwort von starker verbender Kraft angesehen.

Dass die polnische Legionen bisher den österreichischen Landsturmeid leisteten, wurde in den kreisen der Polen vielfach unangenhm empfunden und von Übelwollenden zur Gegenpropaganda ausgenützt. Ich glaube daher für das polnische Hilfskorps die aus der Beilage ersichtliche Eidesformel vorschlagen zu sollen, die sich ganz an den Eid des k.u.k. Heeres anlehnt 
und nur den durch die Tatsachen legitimierten Kampf des Hilfskorps gegen die russische Herrschaft in Polen zum Ausdruck bringt. Seinen Wesen nach bleibt aber der Eid - als ein Seiner k.u.k. Apostolischen Majestät geleistetes Gelöbnis - unverändert.

Das AOK stellt die Bitte, Seiner k.u.k. Apostolischen Majestät im Gegenstande referieren und die Allerhöchste Genehmigung der geplanten Massnahmen einholen zu wollen. 1 Beilage.

Kopia, maszynopis.

Haus - Hof - und Staatsarchiv, Krieg PA I, karton 901, plik Polnische Legionen, folium 8.

Beilage:

Eid des Polnischen Hilfskorps

Wir schwören zu Gott dem Allmächtigen einen feierlichen Eid, Seiner k.u.k. Apostolischen Majestät

\section{FRANZ JOSEF DEM ERSTEN,}

Von Gottes Gnade Kaiser von Österreich, König von Böhmen und so weiter und Apostolischen König von Ungarn als unserem Kriegsherrn treu und gehorsam zu sein und für die Befreiung Polens von der russischen Herrschaft bis zum letzten Blut tropfen zu kämpfen. Wir schwören auch Allerhöchost ihren Generalen, ïberhaupt allen unseren Vorgesetzten und Höheren zu gehorcchen, dieselben zu ehren und zu beschiitzen, ihren Geboten und Befehlen in allen Diensten Folge zu leisten, gegen jeden Feind, wer immer es sei, und wo immer es Seiner kaiserlichen un königlichen Majestät Wille erfordern mag, zu Wasser un zum Land, bei Tag und bei Nacht, in Schlachten, in Stümen, Gefechten und Unternehmungen jeder Art., mit einem Worte an jedem Orte, zu jeder Zeit und in allen Gelegenheiten tapfer und mannhaft zu streiten, unsere Truppen, Fahnen, Standarten und Geschiitze in keinen Falle zu ferlassen, uns mit dem Feinde nie in das mindeste Einverständnis eizulassen, uns immer so, wie es den Kriegsgesetzen gemäss ist un braven Kriegsleuten zusteht, zu verhalten und auf diese Weise mit Ehre zu leben und zu sterben. So wahr uns Gott helfe. Amen! 


\section{Dokument nr 3}

1916 wrzesień 20, Cieszyn. - Pismo przewodnie austro-węgierskiej Naczelnej Komendy Armii przeznaczone do austro-wegierskiego Ministerstwa Spraw Zagranicznych zapowiadajqce kontynuacje spraw ujętych w Nocie nr 18254.

In Vervolg der h. St. Note K. Nr 18245 vom 31 August leitenden Jahres zur geneigten Kenntnis ${ }^{2}$.

Objaśniające uzupełnienie autora niniejszej publikacji zaczerpnięte $z$ tej samej strony dokumentu: „Dem k.u.k. Ministerium des Aeussern mit dem Beifügen vorgelegt, dass die obzietierte Note des k.u.k. Armeeoberkommandos dem Ministerium direkt zugegangen sein soll".

Cieszyn, am 21 September 1916.

Podpis D[ionizy] Thurn

Oryginal, maszynopis.

Haus - Hof - und Staatsarchiv, PA I, Krieg 8a, Hilfskorps, karton 901, folium 14 .

\section{Dokument nr 4}

1916 wrzesień 20, Cieszyn. - Pismo austro-węgierskiej Naczelnej Komendy Armii zawierajace informacje o powotaniu przez austriackiego cesarza Polskiego Korpusu Positkowego.

Seine k.u.k. Apostolische Majestät hat über Antrag des AOK nachfolgende Massnahmen bei den polnischen Legionen Allerhöchst genehmigt:

1) Bewilligung zum Tragen Legionsuniform für die bei den polnischen Legionen eingeteilten k.u.k. Offiziere.

2) Verleihung von historischen polnischen Fahnen an die Legionsinfanterieregimenter (auf einer Seite mit dem polnischen Adler, auf der anderen mit dem Bildnis der Heilige Mutter Gottes).

3) Ausgestaltung der Polnischen Legionen in 2 komplette Infanteriedivisionen und Benennung der gesammten in Russisch - Polen aufgestallten Truppen als „Polnisches Hilfkorps”.

2 Podpis nieczytelny. Do tego jednozdaniowego pisma załączone objaśnienie. 
Das Armeeoberkommando verfügt hiezu:

ad 1) Diese Offiziere sind von nun an als „Überkomplett”, zum Polnischen Hilfskorps abkommandiert zu führen. Im Übrigen kommen diesen Offiziere die Rechte und Pflichten der k.u.k. (k.k., k.u. ${ }^{3}$ ) Offiziere nach wie vor zu. Welche Legionsoffizierscharge diesen Offizieren auf Kriegsdauer verliehen wird, wird das AOK in jedem Falle bestimmen.

Das Kommando der Polnischen Legionen hat ehestens Nominallisten der dort eingeteilten Offiziere und zwar gesondert für Heer, k.k. un k.u. LW mit nachfolgenden Rubriken vorzulegen:

Charge, Rang - Datum und Nummer, Name, Standesverhältnis (Berufsoff $z^{4}$, gewesener B.O., Reserwe oder Ruhestand), Diensteseinteilung, dient in der Legion seit..., zuständiger Standeskörper, Antrag des Legionskommandos, Anmerkung.

Das Legionskommando hat bei seinen Anträgen auf Verleihung einer höheren Legionsoffizierscharge die bisherige Dauer der Offiziersdienstzeit zu berücksichtigen; etweige Ungleichmässigkeiten sind zu begründen.

ad 2) Das Kommando der Polnischen Legionen hat ehestens einen färbigen Entwurf für die Legionsfahnen, der sich tunlichst an historische polnische Fahnen anlehnen soll, zur Genehmigung anher vorzulegen; dem Entwurf ist eine Beschreibung der Fahnen beizulegen, in welchem die historischen Teile besonders hervorzuheben sind.

ad 3) Weisungen für die Ausgestaltung der Legionen werden folgen. Bis dahin bleibt die Bezeichnung "Kommando der Polnischen Legionen" aufrecht.

Ergeht an das Kommando ud Gruppenkommando der Polnischen Legionen, die Militärische Sektion des $\mathrm{OPNK}^{5}$ und zur Kenntnis an das k.u.k. Kriegsministerium, das k.k. Ministerium für Landesverteidigung, den k.u. Landesverteidigungsminister, das k.u.k. Ministerium des Äussern und den Vertreter des AOK beim kaiserliche deutsche Generalgouvernement Warschau $^{6}$.

Oryginał, maszynopis.

Haus - Hof - und Staatsarchiv, Krieg 8a, PA I, karton 901, plik Hilfskorps, folium 15 .

3 W tym skróconym słowie chodzi o oficerów zawodowych (Beruf-soffizieren).

4 Tak w tekście.

5 Oberste Polnische National Komitee $=$ Naczelny Komitet Narodowy $(\mathrm{NKN})$.

6 Podpis nieczytelny. 


\section{Dokument nr 5}

1916 wrzesień 21, Cieszyn. - Pismo przedstawiciela austro-wegierskiego Ministerstwa Spraw Zagranicznych przy austro-wegierskiej Naczelnej Komendzie Armii Dionisego Thurna do austro-wegierskiego ministra spraw zagranicznych barona Stefana Buriana w sprawach dotyczacych przemianowania Legionów Polskich na Polski Korpus Positkowy.

Wie Euer Exzellenz durch die Note des k.u.k. Armeeoberkommandos, K. Nr 18 254, vom 31 August bekannt wurde, hat sich das Armeeoberkommando zu Ende des vorigen Monats die Allerhöchste Genehmigung zu einer Reihe von Massmahmen erbeten, welche auf die Ausgestaltung der Polnischen Legon zu einem "Polnischen Hilfskorps" abzielten, eine Gedanke, welcher von verschiedenen politisch massgebenden Seiten seit längerer Zeit propagiert wurde von dessen bevorstehender Realisierung Herr von Ugron durch das Privatschreiben Herrn von Wiesners vom 25 August leitenden Jahres avisiert worden war. Seine k.u.k. Apostolische Majestät haben sohin allergnädigst zu genehmigen geruht., dass die vom Armeeoberkommando in Vorschlag gebrachten Massnahmen getroffen werden.

Kurz darauf wurde die Frage der Verlautbarung dieser Allerhösten Entschliessung, welche der Öffentlichkeit zunächst nicht bekanntgegben worden war, aus Gründen innerpolitischen Natur akut. Auf Grund eines Privatschreiben des Herrn von Ugrons vom 17 leitendes Monats hat Herr Wiesner die Publikationesfrage bei Oberst von Hranilović zur Sprache gebracht und nach den ihm erteilten Informationen am 19 dieses Monats telephonisch gemeldet, dass eine Press - Enunziation, wie sie von verschiedenen Seiten beim Armee - oberkommando angeregt war und wie sie auch dem Ministerium des Äussern erwünscht erschiene, am 20 dieses Monats publiziert werden wïrde, was denn auch in den gestrigen Morgenblättern geschah.

Wie ich nun heute vormittags in streng vertraulicher Weise erfahren habe, soll dieses Communqué bei der deutschen Obersten Heeresleitung lebhafte Mißstimung erregt haben, weil sie darin - ob in der Sache selbst oder in deren Publizierung allein ist mir nicht bekannt - einen Vorgang erblickt, welcher den zwischen Euer Exzellenz un Herrn von Bethmann ${ }^{7}$ getroffenen Abmachungen ïber die polnische Frage widerspreche. Eine in diesem Sinne gehaltene Vorstellung der deutschen Heeresleitung soll dem Armeeoberkommando zugegangen sein.

7 Chodzi o niemieckiego kanclerza Theobalda Bethmanna-Hollwega. 
Während mir, wie gesagt, vom diesem Schritte der Obersten deuutschen Heeresleitung keinerlei offizielle Verständigung zuging, liess der Chef der Nachrichten - Abteilung, welcher in den Angelegenheiten der Polnischen Legion als Referent des Armeeoberkommandos fungiert, heute Nachmittags Herrn von Wiesner zu sich bitten und hat sich ihm gegeniiber, ohne hiebei auch nur andeutungsweise auf eine bereits erfolgte Démarche aus Pless anzuspielen, in nachstehender Weise geäussert.

Nach seiner - des Obersten von Hranilović - persönlichen Auffassung sei die erfolgte Ausgestaltung der Polnischen Legion und die Publizierung dieser Massnahme ein Gegenstand, welcher auf deutscher Seite möglicherweise Rekriminationen auslösen könne. Im Hinblicke auf diese, rein akademisch besprochene Eventualität lege er Gewicht darauf festzustellen, dass das Armeoberkommando in dieser Frage im Sinne der Intentionen des Ministeriums des Äusern vorgegangen sei und dieses Ministerium auch stets iiber die im Gegenstande unternommenen Schritte im Laufenden erhalten habe. Er - Oberst Hranilović - sei bei Behandlung dieser Angelegenheit von der Auffassung ausgegangen, dass die Ausgestaltung der Legion eine Frage sei, welche abseits des in Lösung begriffen grossen polnischen Probems liege, eine Sache, welche rein internen Charakter trage und von der Monarchie allein zu regeln sei, dies aber selbstverständlich derart, dass sie im Rahmen jener Absichten behandelt werde., welche der zwischen Monarchie und Deutschland intentionierten Bereinigung der polnischen Frage zugrunde liegen. Im Sinne dieser Auffassung der Angelegenheit als einer spezifisch österreichisch - umgarischen sei - worauf Oberst von Hranilović Gewicht lege - alleruntertänigst beantragt worden, dass die polnischen Legionäre auch in Hinkunft den Landsturmeid abzulegen haben, eine Anordnung, welche das politische Wesen der Legion unberiihrt gelassen un den rein internen unpräjudizierlichen Charakter der in Rede stehenden Massnahmen zur Genïge dokumentiert habe.

Anknïpfend an diese Darlegung erbat sich Oberst von Hranilović erb für seine Person eine Bestätigung darüber, dass diese seine Auffassung jener des Ministeriums de Äussern entspreche und dass er bei Behandlung dieser Angelegenheit sowie speziell auch in der Frage der Publikation der Allerhöchsten Entschliessung im Einvernehmen mit dem Ministerium des Äussern vorgegangen sei.

Obwohl die vorstehend wiedergegebenen Ausführungen des Chefs der Nachrichten - Abteilung der Sachlage, soweit sie nach dem hier vorliegenden Informationen Überblickt und beurteilt zu werden vermag, vollkommen entsprachen und es speziell in Hinblicke auf das frïher erwähnte Privat- 
schreiben Herrn von Ugrons in den Intentionenn Euer Exzellenz lag, dass die mehrerwähnte Allerhöchste Entschliessung in der Tagespresse verlautbart werde, so hat Sektionsrat von Wiesner den Wunsch des Obersten von Hranilović selbstverständlich nur ad referendum genommen, dies umsomhr, als die an ihn gerichtete Frage in eine rein theoretische Form gekleidet war un den eigentlichen Kernpunkt der Differenz zwischen den beiden Heeresleitungen nicht direkt beriihrte, ob. nämlich die Zustimmung der deutschen Regierung oder der deutschen Heeresleitung zur Ausgestaltung der Legionen und zur Publikation dieser Massregel einzuholen gewesen wäre oder nicht.

Wie Euer Exzellenz meinen vorstehenden Ausführungen entnehmen wollen, handelt es sich bei der von Oberst von Hranilović in der Gestalt eines persönlichen Wunsches gestellten Anfrage offenbar um eine Sondierung des Armeeoberkommandos, welches wohl vorläufig die Sicherheit haben möchte, dass Hochdieselben im Falle einer deutscherseits erhobenen Rekrimination den Standpunkt des Armeeoberkommandos als gerechtfertigt anerkennen werden, wonach es die Ausgestaltung der Legionen und die Publizierung dieser Verfügung anordnete, ohne hierüber das Einvernehmen mit der deutschen Heeresleitung zu pflegen.

Indem ich mich beehre, Euer Exzellenz von Vorstehendem Meldung zu erstatten, darf ich Hochdieselben um eine telegraphische Weisung bitten, in welcher Form die Anfrage des Obersten von Hranilović beantwortet werden kann.

$$
\mathrm{D}[\text { ionizy] Thurn }
$$

Oryginał, maszynopis.

Haus - Hof - und Staatsarchiv, Krieg, PA I, karton 901; plik: Verhandlungen mit deutscher Regierung im Frage der Legion, folium 16-18.

\section{Dokument nr 6}

1916 wrzesień 22, Berlin. - Rozszyfrowana depesza nr 284 austro-wegierskiego ambasadora w Berlinie, księcia Gottfrieda Hohenlohe - Schillingfürsta do austro-węgierskiego Ministerstwa Spraw Zagranicznych o reakcji niemieckich czynników na publikację o rozbudowie Legionów Polskich.

Der Reichskanzler und Herr von Jagow $^{8}$ sind in höchster Aufregung

8 Gottlieb von Jagow był sekretarzem stanu w niemieckim Urzędzie Spraw Zagranicznych. 
ïber die Publizierung bezïglich der Polnischen Legionen, in der unter anderem auch von einer Erweiterung derselben die Rede ist, nachdem dies Verfügungen im direkten Widerspruch mit den Abmachungen ständen, die Euer Exzellenz mit dem Kanzler in Wien ïber die Schaffung einer polnischen Armee getroffen hätten; man könne sich hier nicht vorstellen, dass Euer Exzellenz jetzt, wo man eben daran gehe, durch eine gemeinsame Kommission die Frage der polnischen Armee zu regeln, der oberwänten Publizierung zugestimmen hätten.

Der Reichskanzler habe auch bereits selbst an Herrn vo Tschirsky ${ }^{9}$ telegrafiert und ihn beuftragt, Euer Exzellenz zu bitten, dieses Missverständnis aufzuklären, sowie um eine Behandlung dieser Angelegenheit zu bitten, die den getroffenen Abmachungen entspreche.

Herr von Jagow fügte hinzu, Euer Exzellnz würden wohl zugeben, dass durch unsere jiingste Publizierung die ganze Frage der Schaffung einer polnischen Armee präjudiziert sie, eine Ansicht, die auch Feldmarschall Hindenburg und sein Generalstabschef vertreten.

Oryginał rozszyfrowanej depeszy, maszynopis.

Haus - Hof - und Staatsarchiv, Krieg PA I, karton 901; plik: Verhandlungen mit deutscher Regierung im Frage der Legion, folium 21.

\section{Dokument $\mathrm{nr} 7$}

1916 wrzesień 23, Wiedeń. - Zaszyfrowany telegram austro-węgierskiego Ministerstwa Spraw Zagranicznych do ambasadora księcia Gottfrieda Hohenlohe - Schillingfürsta w odpowiedzi na depesze nr 284.

Euer Durchlaucht Telegramm Nr 284 erhalten.

Die auf die Polnische Legionen bezughabende Verfïgung des Armee Oberkommandos steht keineswegs im Wiederspruche mit den letzten Wiener Abmachungen. Diese bezogen sich lediglich auf eine erst zu errichtende polnische Armee.

Die Legionen waren und sind noch immer ein Bestandteil der k.u.k. Armee und unterstehen in jeder Beziehung ausschlisslich den Armee - Oberkommando. Wie seinerzait ihre Errichtung, so liegt jetzt ihre Erweiterung

9 Heinrich von Tschirschky und Bogendorff był niemieckim ambasadorem w Wiedniu. 
in der Kompetenz unserer Heeresleitung. Dieselbe tangiert die Errichtung einer polnischen Armee nicht. Die Ausfüllung der sehr gelichteten Kader der Legionen würde vielmehr der Bildung einer polnischen Armee sehr zu statten kommen.

Mit dem Augenblicke der Errichtung der letzteren wird selbstverständlich das einseitige Verfügungsrecht des Armee - Oberkommandos verabredentermassen aufhören.

Ich kann nicht einsehen, wie die Frage der Schaffung einer polnischen Armee durch die fraglichen Massnahmen und ihre Publizierung präjudiziert sein könte.

Dieselben waren aus politischen Rïcksichten dringend geboten und haben die öffentliche Meinung in Galizien sehr befriedigt und dürften die Dispositionen für die Errichtung der polnischen Armee auch im Königreiche gïnstig beeinflussen.

Euer Durchlaucht wollen den Reichskanzler und Herrn von Jagow im Sinne des Vorstehenden aufklären und sie zu beruhigen trachten.

[Baron Stefan Burian]

Koncept zaszyfrowanej depeszy, maszynopis.

Haus - Hof - und Staatsarchiv, Krieg, PA I, karton 901; plik 8a: Verhandlungen mit deutscher Regierung im Frage der Legion, folium 20.

\section{Dokument nr 7}

1916 wrzesien 23, Kraków. - Informacja o reakcji Polaków na wieść o·przemianowaniu Legionów Polskich.

Die Ankïndigung der reform der Legionen ist von der polnische Presse beifällig aufgenommen worden. Mit Ausnahme das "Głos Narodu”, welcher sich bisher nicht geäussert hat, brachten alle polnische Blätter in Galizien und im k.u.k. Okkupationsgebiete zustimmende Artikel. Sogar der jetzt frondierende sozial - demokratische „Naprzód” betonnte die Bedeutung der Reform; nebenbei gesagt, schreibt er das Zustandekommen derselben vor allem Pilsudski zu.

Die gemässigten Kreise des Obersten Nationalkomitees stehen der Reform der Legionen mit gemischten Gefühlen gegenüber. Ihr Urteil spitzt sich in den Worten zu: „Zu spät”. Noch vor zwei Monaten würde die Reform 
eine neue Aera bedeuten und die Konsolidierung der Polen Kongress - Polens und Galiziens herbeiführen. Leider wurde mit der Reform gezögert und mittlerweile sind in Galizien und in Kongress-Polen Strömungen erstarkt, welche das Program des Obersten Nationalkomitees bekämpfen.

Der allgemeine Eindruck geht dahin: die österreichisch - ungaarische Lösung der polnischen Frage ist abgetan. Jetzt heisst es nur, die Trummer des Progarmmes zu retten und dem Obersten Nationalkomitee einen Ausweg aus der Sackgasse zu ermöglichen. Die Wiener Sitzungen der politischen Kommission des Polenklube standen unter diesem Eindruck.

Die linksstehenden Elemente des Obersten Nationalkomitees versuchten in der Sitzung der politischen Kommission, einen weitgehenden Antrag auf sofortige Einsetzung einer Nationalregierung in Kongress - Polen im Einversändnisse mit Galizien durchzussetzen. Der Antrag fiel durch, dafür wurde eine Resolution Leo ${ }^{10}$ angenommen, deren Sinn der ist, dass man nicht gewillt ist, ïber den Antrag der Sozialdemokraten abzustimmen.

Die Sozialdemokraten zogen aus der Ablehnung ihres Antrages keine Konsequenzen, setzen aber in ihren Blättern die Campagne gegen die Gemässigten fort. Ihre Idee ist, ein Zusammengehen des Zentralen Nationalkomitees (Centralny Komitet Narodowy - CKN) mit der Liga der polnischen Staat-lichkeit, welche am 17 September einen imposanten Parteitag in Piotrków abhielt, herbeizuführen. Als Bedingung der Einigung fordern sie die Auflösung des Militärdepartaments und die Übertragung des Kommandos des polnischen Hilfskorps an Piłsudski.

Piłsudski schmollt in Zakopane. Heute soll dorthin Oberst Hranilović gereist sein, um den Brigadier zu „basänftigen”. Nach der Meinung der gemässigten polnischen Politiker wäre die Übertragung der Leitung des Hilfskorps an Piłsudski ein Dring der Unmöglichkeit und würde zu argen Reibungen führen. Als Kommandanten kämen in Betracht: Puchalski, Rozwadowski oder Szeptycki. Piłsudski könnte höchstens eine Division bekommen. Die Anhänger Piłsudskis sind natürlich anderer Meinung. Leider muss gesagt werden, dass Piłsudski gerade von seinen jetzigen Gegnern (Militädepartement) so ïber dem Klee gelobt wurde, dass er jetzt wie ein Symbol, fast wie ein nationales Heiligtum dasteht. Er weiss dies (denn er ist ein geriebener Politiker) und versteht sehr gut, seinen Ruhm politisch auszuniitzen. Er wird von Oberst Hranilović manches zu erpressen versuchen. Leo.

10 Chodzi o prezydenta miasta Krakowa i pierwszego prezesa NKN profesora Juliusza 
Der wunde Punkt der Reform der Legionen ist die Werbetätigkeit. Piłsudski und seine Leute haben es glïcklich dazu gebracht, dass die Werbetätigkeit in Kongress - Polen ins Stocken geraten ist. Es besteht ein direktes Verbot des Eintrittes in die Legionen. Piłsudskileute nehmen die Namen der Freiwilligen auf und erklären ihnen, dass sie nicht erst dann melden sollen, wenn Piłsudski es erlauben wird. Angeblich sind auf diese Art 7000 Jünglinge aufgenommen - sie warten auf ein Wort Piłsudskis, um in die Legionen einzutreten. Vorläufig sitzen sie zu Hause, stolzieren herum und fühlen sich unendlich höher als die gemeinen Legionäre. Auch so eine Art. Von Drückebergern; się haben sehr gut Prinzipientreue mit dem Drückebergertum vereinigt.

Nach Behauptungen der Piłsudskileute gibt es 7000 solcher Leute; eine winzige Schar im Vergleich zu der Zahl der wehrfähigen Männer in Kongress - Polen!

Wenn es ernst würde, dann würde auch diese Zahl auf die Hälfte sinken. Ein grösseres Fiasko der Piłsudskiaktion kann man sich kaum denken. Ein ebensolches Fiasko erlitt Piłsudski am Anfang des Krieges, als er nach Kongress - Polen zog, um einen Aufstand zu „machen”. Das Verbot der Werbetätigkeit, denn sonst würde sich zeigen, wie einflusslos er in Kongres - Polen ist. Aus ebediesen Grunde wird er auch Hranilović gegenïber den Prinzipienfesten spielen.

Heute soll aus Warschau eine Deputation nach Berlin abgereist sein, an der Łempicki, Brudziński, Ronikier und Radziwiłł teilnehmen. Der Zweck der Deputation ist, Klarheit ïber die Absichten Deutschlands ïber Polen $\dot{z u}$ erlangen. Das Warschauer Oberste National-komitee wiess von dieser Deputation und hat ihr sogar Instruktionen mitgegeben: sie möge sich nich zuviel engagiren. Von Berlin kommen die Herren nach Krakau und reisen sodann mit Vertretern des Obersten Nationalkomitees nach Wien, um auch dort vorzusprechen.

Podpisu autora informacji brak

Odpis, maszynopis.

Haus - Hof - und Staatsarchiv, Krieg PA I, karton 901, plik 8a, folium 102-103. 


\section{Dokument $\mathrm{nr} 8$}

1916 wrzesień 24, Warszawa. - Informacja przedstawiciela austro-wegierskiego Ministerstwa Spraw Zagranicznych o odczuciach spoteczeństwa polskiego na wieść o przemianowaniu Legionów Polskich.

An Seine Exzellenz den Herrn Minister des k.und k. Hauses und Äussern Stephan Baron Burian von Rajecz.

Als hier vor einigen Tagen die Durchführung der schon seit langen projectierten Neu-orgasnisation der polnischen Legionen bekannt wurde, wirkte diese Nachricht, trotzdem schon früher Gerïchte über die geplanten nationalen Zugeständnisse an die Legionen in die hiesigen politischen Kreise gedrungen waren, doch sehr ïberraschennd. Der Eindruck in den politischen $\ldots{ }^{11}$ ist ein iiberaus günstiger: die allgemeine Auffassung ist die, dass die Ausgestaltung der Legionen in ein Polnisches Hilfscorps ein weitgehendes nationales Zugestä ndnis an die Polen bedeute, an welches sich möglicherweise noch die Befriedigung anderer polnischen Wünsche bald anschliessen werde. Auch wird betonnt, dass die endliche Verwirklichung der Reorganisation der Polnischen Legionen wesentlich zur Stärkung der Legionsidee im Königreiche beitragen und die Werbung begünstigen dürfte. Selbst in den Kreisen der Rechten wird - vorläufig allerdings nur zaghaft - der Anschauung Ausdruck gegeben, dass man jetzt die Legionen tatsächlich als die Grundlage zur Bildung einer kün- ftigen nationalen Armee betrachten könne. Wie ich weiters erfahre, wurde unter mehreren ernsten Politikern die Frage erwogen, obeEs nicht rathsam wäre, an Piłsudski ein Schreiben zu richten, um ihm daran zu mahnen, dass jetzt ein Zeitpunkt gekommen sie, in welchem alle Streitigkeiten und Missverständnisse innerhalb der Legionen verschwinden müssten.

Für die politischen Ziele der Monarchie in Polen hat die Befriedigung der nationalen Aspirationen der Legionen auch die Bedeutung, dass man jetzt mit der durch die Deutschen verbreiteten Fabel, dass es Österreich - Ungarn sei, welches für die Realisierung der polnischen Wünschen ein Hindernis bilde, gänzlich wird aufräumen können.

Im Gegensatze zu der polnischen Öffentlichkeit erregte das Bekanntwerden der Reformen in den Legionen, bei den hiesigen deutschen Stellen eine arge Misstimmung. Oberst con Paić ${ }^{12}$ erzehlte mir, dass der Generalgouver-

11 Nieczytelne słowo.

12 Josef Paić był przedstawicielem austro-węgierskiej Naczelnej Komendy Armii w Warszawie. 
neur im Gespräche mit ihm diese Frage zunächst gar nicht berührte, dass er aber, als unser militärischer Vertreter dann selbst auf die Sache zu sprechen kam, sagte, dass die Nachricht ihm einen „starken Rucker” gegeben und dass sie ihn umso mehr überrascht habe, als in letzten Zeit nichts ïber die geplante Neuorganisation der Legionen verlautete. Oberst von Paić erwiderte, dass die Reformen rein militärische Masnahmen seien, die zur Vermeidung weiterer Differenzen zwischen einzelnen Gruppen der Legionen und Hintanhaltung der eventuellen Auflösung derselben unbedingt notwengig waren, und dass von diesem Standpunkte ein ferneres Hinausschieben der Umgestaltung der Legionen auf nationaler Basis nur unerwünschte Folgen hätte zeitgen können.

Die deutsche Censur hat die Besprechung der Frage in den hiesigen Zeitungen untersagt und nur die Wiedergabe der bezüglichen telegraphischen Nachricht, die ïbrigens in einer unbeabsichtigt verstïmmelten Form in den Blätterrn erschien, zugelassen. Da aber die Öffentlichkeit aus Stimmen galizischer Zeitunen sich ihr Urteil wird bilden können, so glaube ich, dass das Verbot der deutscher Censur eine ziemlich unkluge Massnahme darstellt, die vom Standpunkte der deutschen Interessen eher zu vermeiden gewesen wäre.

Der k.und k. Legationssecretär Michałowski

Oryginał, maszynopis.

Haus - Hof - und Staatsarchiv, Krieg PAI, karton 901, plik 8a, Polnische Legionen, folium 23-24.

\section{Dokument nr 9}

1916 wrzesień 25, Cieszyn. - Szyfrowana depesza hrabiego Thurna do austro-wegierskiego ministra spraw zagranicznych barona Stefana Buriana o wzmiankach dotyczacych spraw przemianowania Legionów Polskich w rozmowie arcyksięcia Fryderyka Habsburga z niemieckim cesarzem Wilhelmem II.

Streng vertraulich.

Die gestrige Besprechung Seiner k. und k. Hoheit Erzherzogs Friedrich mit Seiner Majestät dem deutschen Kaiser hat obwohl się freundschaftlichsten Charakter trug, noch nicht die volle Beilegung der durch Erlassung der 
neuen Legionsbestimmungen hervorgerufenen Differenzen gebracht.

Wie aus den mir gewordenen streng vertraulichen Mitteilungen Seiner k. und k. Hoheit hervorgeht, scheint man deutscherseits in unserem bezüglichen Vorgehen nicht nur einen durch das Verschweigen unserer Absichten dem Bundesgenossen gegenüber bewiesenen Mangel an Loyalität zu erblicken, sondern sich auch in den eigenen politischen Interessen schwer geschädigt zu erachten. Letztere Auffassung findet ihre Erklärung wohl darin, dass, wie es scheint, man sich in Deutschland schon seit einiger Zeit mit dem Gedanken getragen hat, auch im deutschen Verwaltungsgebiete polnische Legionen aufzustellen. Diese Absicht wurde gestern zum ersten Male durch Kaiser Wilhelm dem Herrn Erzherzog gegenüiber erwähnt, und am selben Abends auch durch die Oberste Heeresleitung anher offiziell bekanntgegeben.

Man empfindet nun offenbar die unsere Polnischen Legionen gewährten Konzessionen entweder aus dem Grunde sehr unangenehm, weil durch deren unvermeindliche Berïcksichtigung bei der geplanten Austellung von Legionen im deutschen Verwaltungs-gebiete das Mass des deutscherseits beabsichtigten Entgegenkommens ïberstiegen werden müsste, oder aber deshalb, weil durch die unserseits bereits erfolgte einseitige Gewährung dieser Zugeständnisse den Deutschen ein wirksames Mittel für die Stimmungmache zu Gunsten ihrer Legionen vorweggenommen wurde.

Ist nach dem Vorgesagten auch einigermassen verständlich, wieso sich die Deutschen durch unsere Massregel geschädigt fühlen können, so ist es doch nicht recht klar, was General von Ludendorff ${ }^{13}$ damit meinte, als er gestern dem Generaladjutanten Grafen Herberstein gegenüber, der den Herrn Erzherzog nach Pless begleitet hatte, bei Besprechung der Angelegeneheit die Bemerkung fallen liess, dass, wenn auch nach den inzwischen erfolgten Auklärungen unserseits gewiss keine böse Absicht vorgelegen habe, der Deutschlandn durch unser einseitiges Vorgehen zugefügte Schade doch wieder gut gemacht werden müsste.

Über den weiteren Verlauf dieser leidigen Angelegenheit werde ich, sobald ich näheres erfahre, Euer Exzellenz berichten.

[Graf Thurn]

Kopia, maszynopis.

Haus - Hof - und Staatsachiv, Krieg PA I, karton 901, plik 8a, folium 25.

13 W stosunku do generała Ericha Ludendorffa autor dokumenu użył określenia „von"; jest to nieścisłość, ponieważ Ludendorff nie był człowiekiem szlacheckiego pochodzenia. 


\section{Dokument nr 10}

1916 wrzesień 26, Cieszyn. - Pismo austro-wegierskiej Naczelnej Komendy Armii do austro-wegierskiego ministra spraw zagranicznych barona Stefana Buriana von Rajecz o usunieciu brygadiera Józefa Pitsudskiego z Legionów Polskich.

Das Armeoberkommando beehrt sich, Euer Exzellenz anruhend eine Abschrift des an dem Legionsoberstbrigadier der Polnischen Legionen Josef Piłsudski ergangenen Befehls zu iiberreichen, in welchem demselben die von ihm erbetene Demission als Kommandant der I Brigade der Polnischen Legionen und die Entlassung aus dem Legionsvebande bewillgt werden.

Der Grund hiezu ist folgender:

Legionsoberstbrigadier von Piłsudski hat aus Anlass einer dienstlichen Differenz mit dem ihm vorgesetzten Legionskommandanten General Major von Puchalski, an das Armeeoberkommando die Bitte um Entlassung aus dem Legionsverbande gerichtet. Die Ursache, dass das Armeeoberkomando dieser Bitte Folge gegeben hat, obwohl die militärischen Verdienste Piłsudskis, welcher seit Beginn des Krieges als Fïhrer zuerst der polnischen Freiwilligenformationen, später des daraus entstandenen 1 Legionsregiments und schliesslich der I Legionsbrigade nicht nur sehr gut entsprochen, sondern auch durch seine persönliche Tapferkeit und durch sein Geschick als Fïhrer effektive Erfolge errungen hat, volle Anerkennung verdienen, liegt ausschlisslich darin, dass er mit den steigenden Erfolgen und der damit Hand in Hand gehenden Popularität, welche sich allerdings hauptsächlich in den sozialistischen Kreisen ausbreitete, jedes zulässige Mass in der Einschätzung seiner persnlichen Bedeutung und seines Wertes iiberschritt, immer mehr das Streben nicht nur nach dem Legionskommando, sondern ïberhaupt nach der Diktatur in Russisch - Polen enthïllte, sich für seine Sonderzwecke einer ausgebreiteten geheimen Agitation bediente und dadurch nachgerade zu einer Gefahr für den Bestand der Legionen wurde. In seinem uferlosen Ehrgeiz setzte sich Piłsudski in letzter Zeit nicht nur in ununterbrochenen heftigen Gegensatz zum vorgesetzten Legionskommando, sondern auch zu den ruhig denkenden politischen Kreisen seines eigenen polnischen Vaterlandes, sowie zur Mehrzahl der Mitglieder des Obersten Polnischen Natinalkomitees, sobald diese seinen persönlichen Bestrebungen nicht Folge leisteten.

Den ersten Anlass zur Entlassung gab die mündliche Meldung des Kommandanten der Polnischen Legionen, General Major von Puchalski, welcher iiber das Verhalten Piłsudskis beim Armeeoberkommando am 24 August lei- 
tenden Jahres Folgendes vorbrachte: „Der Brigadier Piłsudski hat nicht nur jedem Legionsangehörigen und allen massgebenden politischen Personen, sondern auch dem General Major von Puchalski und dem Oberstbrigadier Graf Szeptycki gegenüber ganz offen geäussert, dass das Legionskommando nur ihm gebiihre. Dies offen ausgedrückte Ansicht hat er durch sein Benehmen vollauf bestätigt, indem er bei jeder Gelegenheit sich dem Befehlsrechte seiner Legionsvorgesetzten entzog oder zumundest die Befehle nur formell, aber nich ihren Sinne gemäss befolgte. Bei jeder Gelegenheit zeigte er das Bestreben, die zur I Brigade gehörigen Abteilungen als etwas von den ïbrigen Legionen Abgesondertes, nur ihm allein Unterstehendes, zu behandeln und machte das Verfügungsrecht über dieselben dem Legionskommando streitig. Überdies suchte er seit jeher diesen Einfluss auch in die iibrigen Teile der Legionen zu verpflanzen und bediente sich hiezu der eifrigsten offenen und geheimen Agitation. Um die Legionen in ihrer jetzigen Form unpopulär zu machen un deren Entwicklung zu verhindern, eröffnete er im Jahre 1915 die heftige Agitation gegen jede Werbung un suchte in dieser Hinsicht die öffentliche Meinun Russisch - Polens auf seine Seite zu bringen. In seiner Brigade führte er ein despotisches Untedrïckungssystem gegen jedermann ein, der nicht blind seiner Meinung folgte und gieng darin so weit, dass er auch vordienste Männer seiner Brigade um die ihnen für ihre Leistungen gebiihrenden Auszeichnungen brachte, an deren Stelle er ein eigenen Brigadeabzeichen mit Statuten, welche jenen wirklicher Orden ganz gleichen, einführte,

Diese Wühlereien untergraben auf die Dauer jede Autorität und können nicht nur im Interesse der Einheit der Legionen, sondern auch im militärischen und taktischen Interesse unmöglich weiter toleriert werden; umsoweniger als bei dem gewlttätigen Charakter Piłsudskis zu befürchten ist, dass er eventuell auch in gefährlichen Momenten den Gehorsam versagt, wenn er einen Befehl erhält, der seiner Auffassung nicht entspricht, und auf diese Weise Ereignisse von unabsehbarrer Tragweite herbeiführt. Um allen diesen Unzukömmlich-keiten und Gefahren zu begegnen, ist nur die eine Lösung möglich, Piłsudskis Entlassung aus den Legionen sofort zu verfügen".

Die zweite Anlass ist der in Abschrift beiligende Bericht des Kornmandos der Polnischen Legionen (Gstbs, Nr 96 vom 14 September leitendes Jahres) ${ }^{14}$, der ïber Auftrag des vorgesetzten Korpskommandos General der

14 Por. dokument nr 24, publ. M. Wrzosek, w: „Studia Podlaskie”, tom X, Białystok 2000 , s. $330-337$. 
Infaterie Fath ${ }^{15}$ verfasst, sowie die Begutachtungen der vorgesetzten deutschen Kommandos (Armeegruppe Brnhardi, Heeresgruppe Linsingen und Oberbefehlshaber Ost), die sich entschieden für die Entlassung Piłsudskis ausgesprochen haben.

Auch die deutsche Oberste Heeresleitung hat bei Vorlage des vorerwähnten Berichtes Verabschiedung des Legionnsbrigadiers von Pilsudski, die als dringend erforderlich bezeichnet wurde, erbeten.

Die Armeeoberkommando konnte unter diesen Verhältnissen aus militärischen, wie aus politischen Grïnden eine Beibehaltung Piłsudskis nichtin Aussicht nehmen und erachtet den Zeitpunkt für seine Entlassung für umso geeigneter, als Seine k.u.k. Apostolische Majestät die Bewiligung zum Tragen der Legionenuniform für die bei den Legionen eingestelten k.u.k. Offiziere, die Verleihung von historischen polnischen Fahnen und die Ausgestaltung der Polnischen Legionen zum „Polnischen Hilfskorps” zu genehnigen geruht haben, demnach den nationalen Wünschen der Polen in weitgehendsten Masse entgegengekommen wurde.

Ergeht gleichlautend an den k.u.k. Minister des Äussern und an den Vorstand der Militärkanzlei Seiner Majestät.

Podpisał Tschirschky

Kopia, maszynopis.

Haus - Hof - und Staatsarchiv, Krieg, PA I, karton 901, plik 8a, folium 118.

\section{Zatacznik nr 1 do dokumentu nr 10}

1916 wrzesień 26, Cieszyn. - Pismo austro-wegierskiej Naczelnej Komendy Armii do brygadiera Józefa Pitsudskiego stwierdzające przyjęcie jego prośby o zwolnienie z Legionów Polskich.

Das Armeeoberkommando hat das von Euer Hochwohlgeboren unter Op. Nr 224 vom 29 Juli leitendes Jahres an das Kommnado der Polnischen Legionen gerichtete Gesuch, das von dort anher vorgelegt wurde, zur Kenntnis genommen und sieht sich bestimmt, in Stattgebung Ihrer Bitte Ihre

15 Chodzi o austro-węgierskiego generała Heirwicha Fatha, który latem 1916 r. dowodził na Wołyniu zgrupowaniem należącym do Grupy Armii generała Aleksandra Linsingena i złożonym $z$ trzech dywizji piechoty. Odpowiadał również za przebieg działań bojowych I Brygady Legionów. 
Demission anzunehmen und Sie aus dem Legionsverbande zu entlassen. Die Vrfügungen betreffs Ihrer Entlassung ergeben unter Einem.

In Würdigung der hervorragenden militärischen Leistungen Euer Hochwohlgeboren als Kommandant der I Brigade der Polnischen Legion kann das Armeeoberkommando nich umhin, seinem Bedauern darüber Ausdruck zu geben., Euer Hochwohlgeboren nach nunmehr zweijähriger Kommandoführung; von Ihren Posten scheiden zu sehen, und nimmt die Gelegenheit wahr, Euer Hochwohlgeboren für Ihre militärischen Verdienste seine vollste Anerkennung auszusprechen.

Podpisał Tschirschky

Kopia, maszynopis.

Haus - Hof - und Staatsarchiv, Krieg, PAI, karton 901, plik 8a, folium [126].

\section{Zatacznik nr 2 do dokumentu nr 10}

Die Demission Piłsudskis.

Am 28 September ist das Oberste Nationalkomitee verständigt worden, dass das Armeeoberkommando die bereits Ende Juli eingereichte Demission des Legionenbrigadiers Piłsudski definitiv angenommen hat. Die Nachricht rief in Krakau grosses Aufsehen sowohl bei den Anhängern wie auch bei den Gegnern Piłsudskis hervor. Die Anhänger waren bisher fest überzeugt, dass das Armeeoberkommando die Demission nicht annehmen werde. In diesen Glauben bestärkte sie die Meldung (die sich allerdings als falsch erwiesen hat), dass Oberst Hranilović eigens nach Zakopane gereist ist, um mit Piłsudski zu konferieren. Wie sich nachher herausgestellt hat, reiste nach Zakopane nicht Hranilović, sondern ein anderer Offizier. Was zwischen diesem Offizier und Piłsudski vorgefallen ist, ist nich bekannt. Die Anhämger Połsudskis erzählen, dass Piłsudski sich absprechend iiber das angekündigte polnische Armeehilfskorps geäussert hat. Er solle gesagt haben, dass Armeehilfskorps an der Sache selbst nichts ändere; nur der Name wird geändert werden, sonst aber wird alles beim alten bleiben. Der Urlaub Piłsudskis lief am 15 Oktobwer ab. Am 27 September begab sich Piłsudski nach Krakau, um von hier aus eine Berufung nach Teschen zu erwarten. Er und seine Anhänger glaubten, dass das Armeeoberkommando nachgeben werde. Ganz unverhofft ist jedoch ein Telegramm von AOK gekommen, in welchem die Annahme der Demission enthalten war.

Nach verbürgten Nachrichten haben auf die Entlassung Piłsudskis die deutschen Militärbehörden gedrängt und entsprechende Eingaben aus rein 
militärischen Gründen an das AOK gesendet. Auch dieser Grund der Demission war für die Anhänger Piłsudskis ein harter Schlag. Er und seine Leute haben nämlich konsequent die Deutschen gegen die "Österreicher" ausgespielt. Forwährend wurde im Lager der I Brigade der Legionen auf die Österreicher geschimpft und gleichzeitig die Deutschen als Muster hingestellt. Manche politisierende Legionäre munkelten davon, dass Piłsudski sich den Deutschen anschlissen wird, wenn die Geschichte zu bunt sein wird. Ebenso hat der politische Exponent Pilsudskis, das Zentrale Nationalkomitee (CKN) ganz off en eine antiösterreichische und deutschfreundliche Politik betrieben. Offiziell haben an die Herren antrüstet geleugnet, man brauchte jedoch nur ihre Publikationen zu lesen, um sich ein richtiges Urteil darüber zu biden. Un nun kamen die Deutschen und schlachteten Piłsudski militärisch ab. In ihrer Verzweiflung verbreiteten sie gestern in Krakau die lächerliche Behauptung, dass die ganze Demission Piłsudskis ein deutsche Teufelwerk sei; die Deutschen wollen Piłsudski von den k.u.k. Legionen entfernen, um ihm die Organisierung einer Armee des unabhängigen polnischeen Staates zu übertragen.

Über die Vorgeschichte der Demission wird erzählt: Am 1 September zeigte sich bei der Auswechslung an dem Legionsabschnitt, das ist bei der Verschiebung des 1 Legionsregimentes und das Kommandos der I Brigade in die Reserve nach Podworsko und bei der Übernahme dieses Abszchnittes durch den Brigadier Haller, dass dieser Abschnitt keine Reserven besitzt. Piłsudski hat die Reserve dieses Abschnittes das ist die Hälfte des ersten Ulanenregimentes auf eigene Faust bereits am 29 August, ohne eine Meldung zu erstatten, zur Erholung ins Dorf zurückgeschickt. Das Kommando der Legionen erstattete darüber einen Bericht an den Kommandanten der Armeegruppe, General Bernhardi. Brnhardi hat die Verfügung Piłsudskis scharf missbilligt und die Enthebung vom Brigadenkommando kategorisch gefordert, Piłsudski habe wenig militärischen Sinn missachte die militärische Disziplin, Bernhardi könne die Verantwortung für die Sicherheit der Front nicht übernehmen, wenn solche Dinge vorkommen. Dieser Meinung trat auch Linsingen als Kommandant der Bug - Armee bei und das Oberkommando Ost (Prinz Leopold von Bayern) hat diese Ansicht approbiert, Ein disbezïgliche Schreiben ging nach Teschen, Piłsudski wurde nach Teschen zitiert, wo ihm die deutschen Dokumente vorgelegt wurden. Der schlaue Legionsbrigadier tat plötzlich sehr österreichischfreundlich, beteuerte, dass er dem Kaiser Franz Joseph und nicht dem Kaiser Wilhelm den Eid geleistet hat und eines österreichisch ungarischen Kommando unterstehen möchte. Schliesslich wurde Pilsudski ein Urlaub bis zum 15 Oktober gewährt. Wie 
bereits oben gemeldet wurde, ist der Urlaub durch die definitive Annahme der Demission jäh unterbrochen worden.

Die Demission Piłsudskis ist ein Wendepunkt in der Geschichte der Legionen. Eine schwere Krise steht bevor, und es wird sich in den nächsten Tagen zeigen, ob es unter den Legionen vernüftige und nüchterne Elemente gibt, welche der Demagogie Piłsudskis und seiner politischen Anhänger Wiederstand leisten werden. Die Piłsudskis - Krise ist gleich-zeitig auch eine Krise im Obersten Nationalkomitee; es wird hoffentlich zu einer reinlichen Scheidung zwischen den gemässigten und radikalen Elementen führen. Piłsudski war die moralische und vielleicht auch die materielle Stütze der sogenannten Unabhängler, die sich um das Zentrale Nationalkomitee (CKN) geschart haben, und die Firma des Obersten Nationalkomitees (NKN) in illoyaler Weise (siehe der Fall Sokolnicki) ${ }^{16}$ missbraucht haben. Es besteht sogar der Verdacht, dass die Gelder der ersten Brigade zu politischen Zwecken gebraucht wurden. Der Rücktritt Piłsudskis wird vielleicht diesem wüsten Treiben ein Ende machen. Wenn Piłsudski die Absicht haben würde, nach der Demission dem politischen Leben sich wieder zuwenden, so müssten Mittel und Wege sich gefunden werden, um dieses Vorhaben zu vereinteln. Ein länger Urlaub in einer ruhigen Ortschaft würde der Gesundheit des Brigadiers sehr gut bekommen.

Es war ein eigenartiger Anblick, wie die Demission Piłsudskis in der paar Krakauuer Kaffehäusern, welche von den polnischen Radikalen und Exaltados besucht werden, aufgenommen wurde. Es wurde gezetert und gelobt und die grösslichsten Drohungen gegen die Gemässigten im Obersten Nationalkomitee sowie auch gegen Österreich - Ungarn ausgestossen. Und doch ist es für jeden objektiven Beobachter eine unleugbare Tatsache, dass dieses Häuflein von Radikalen gar keinen Einfluss auf die breiten Schichten der polnischen Bevölkerung weder in Galizien noch in Kongresspolen besitzt. Się sind von der Bevölkerung abgesondert und leben nur in der Atnsphäre i.hrer eigenen Nervosität. Man hat lange Zeit hindurch den Einfluss dieser Leute überschätzt und ihnen wichtige und veratwortungsvolle Stellen im Obersten Nationalkomitee und in den Legionen anvertraut. Jetzt ist man zu einer anderen Ansicht gelangt; hoff entlich nicht zu spät! Die latente Krise ist zu einer offenen geworden, es wird sich bald zeigen, ob die gemässigten Elemente Kraft genug besitzen, um der Demagogie der Radikalen stadzuhalten.

16 Chodzi o Michała Sokolnickiego, wybitnego piłsudczyka, który był sekretarzem generalnym NKN. 
Die Verlogenheit der Radikalen hat sich am krassesten bei der Ankündigung der Schaffung eines polnischen Armeehilfskorps gezeigt. Wie bakannt, haben die Brigadiere der Legionen mit Umgehung des Dienstweges eine Eingabe an das AOK gemacht, in welcher eine Reform der Legionen im Sinne eines Hilfskorps gefordert wurde. (Nebenbei gesagt, wurde diese Eingabe vom CKN zu Agitationszwecken missbaraucht und massenhaft in Galizien und Kongresspolen kolportiert). Nun erfolgte die Schaffung des Hilfskorps im Sinne der Eingabe; man sollte also glauben, dass die vom Kaiser unterzeichnete Verfügung eine allgemeine Befriedigung auslösen wird. Tatsächlich lauteten in diesem Sinne die Kommentare der ganzen polnischen Presse mit der einzigen Ausnahme des "Głos Narodu”, welcher nur das offizielle Communiqué veröffentlicht hat und sonst mit keiner Silbe dasselbe glossiert hat. Sogar der sozialdemokratische „Naprzód” hat die Reform des Legionen mit Genugtuung begrïsst und selbstverständlich deren Verdienst Pilssudski zugeschrieben. Und nun kommt eine eigentïmliche Wendung: solange Pilsudski Schanzen alz Kommandant des Hilfskorps hatte, war das Hilfskorps gut wünschenswert. Als ein paar Tage nachher es ruchbar wurde, dass nicht Płsudski, sondern ein anderer (Rozwadowski oder Szeptycki) zum Kommandanten ausersehen ist, da verlor das Hilfskorps sowohl für Piłsudski und seine Anhänger jedes Interesse. Auf diese Weise wird eine rein persönliche Politik unter falscher Flage betrieben.

Brak podpisu

Kopia, maszynopis.

Haus - Hof - und Staatsachiv, Krieg, PA I, karton 901, plik 8a, strona 128-133.

\section{Dokument nr 11}

1916 wrzesień 29, Wiedeń. - Anonimowy artykut prasowy z prognozami następstw dymisji brygadiera Józefa Pitsudskiego.

Die gemässigten Elemente des Obersten Nationalkomitees (Jaworski, German und andere) ${ }^{17}$ waren sich seit langem bewusst, dass Piłsudski -

17 Chodzi o Leopolda Jaworskiego, który był profesorem Uniwerstytetu Jagiellońskiego i następcą profesora Juliusza Leo na stanowisku prezesa NKN, a także o galicyjskiego parlamentarzystę polskiego Ludomiła Germana, który był z zawodu pedagogiem, a jednocześnie aktywnym działaczem Stronnictwa Demokratyczno-Narodowego. 
Regime nicht lange andauern werde; sie sind viellleicht in ihrem Innern froh, dass die Sache im jetzigen Moment auf die oben beschriebene Weise zur Entscheidung gelangt ist. Allerdings werden sie sich gegenïber der zu erwartenden publizistischen Sturmflut der Radikalen sehr standhaft halten müssen. Eine klug angewendete Zensur wïrde besonders im jetzigen Moment von unschätzbaren Nutzen sein; bei den jetzigen Zensurverhältnissen in Galizien und teilweise im Okkupationsgebiete wïrde es jedoch wahrscheinlich leider nicht der Fall sein.

Es ist nicht zu erwarten, dass eine Sprengung des Obersten Nationalkomitees erfolgen könnte. Im Vollzugsausschusse des Obersten Nationalkomitees haben die Gemässigten eine grosse Majorität (8 zu 3). Es hat sich diese bei der zweitägigen Debatte des Vollzugsausschusses, die am 25 und 26 September stattgefunden hat, gezeigt. Das Rededuell Jaworski - Daszyński verlief unbedingt zu ungunsten Daszyńskis. Am 3 Oktober wird eine Plenarsitzung des Polenklubs und des Nationalkomitees in Krakau stattfinden, wobei leidenschaftliche Debatten zu gewärtigen sind. Wenn die Sozialdemokraten und Unabhängler aus dem Nationalkomitee und aus dem Poleklub austreten werden, so werden sie sich selbst zu gänzlichen Einflusslosigigkeit verurteilen. Das Oberste Nationalkomitee wïrde sodann an inneren Konsolidierung nur gewinnen. Freilich werden die Radikalen die ungeklärte Lage in der polnischen Frage für ihre Zwecke ausnützen. Das Oberste Nationalkomitee will, wie von massgebenden polnischer Seite betonnt wird, seinem alten Programm auch dann treu bleiben, wenn eine andere Lösung der polnischen Frage erfolgen sollte.

Viel wichtiger als die Frage des Fortbestandes des Obersten Nationalkomitees ist die Frage der Zukunft der Legionen. Wie werden die Legionen die Demission Piłsidskis aufnehmen? Die Anhänger Pilsudskis sind der Ansicht, dass eine Auflösung der Legionen eine unwendbare Sache się. Bei der I Brigade der Legionen dürfte dies vielleicht zutreffen. Wie die anderen zwei Brigaden sich verhalten werden, ist noch ungewiss. Auch in diesen beiden Brigaden werden sich Ahänger Piłsudskis finden; Kenner der Verhältnisse glauben jedoch, dass das Gros der Legionäre ihren Eide treu bleiben wird. Besonders die Offiziere der II und III Brigade solidarisieren sich nicht mit der I Brigade. Dies hat sich bereits bei der angekündigten Demission Połsudskis gezeigt. Piłsudski hat nämlich im August die höheren Legionenoffiziere von seinem Vorhaben benachrichtigt. Von gewisser Seite wurden Haller und Roja aufgefordert, sich mit Piłsudski solidarisch zu erklären und ebrnfalls ihre Demission einzureichen. Die beiden lehnten dieses Ansinnen ab, und zwar mit der Begründung, dass man wie auch bei 
der Einreichung der Demission Piłsudskis um ihre Meinung nicht gefragt hat.

Nichtsdestoweniger muss betonnt werden, dass der Geist der Legionen in der letzten Zeit sehr gesunken ist. Von den Agitatoren des CKN wird in den Legionen seit langem eine systematische Agitation gegen das Obesrste Nationalkomitee betrieben. Sonderbarweise wird diesselbe von Sekretariat des Odersten Nationalkomitees, in welchem sich die Unhängler eigenistet haben (Sokolnicki, Wasilewski) ${ }^{18}$ protegiert. Die physisch erschöpften Legionäre sind solchen Einflusstorungen zugänglich, umsomehr da sie seit zwei Jahren auf eine Lösung der polnischen Frage erfolglos warten.

Die Radikalen Desperados möchten gerne eine blutige Revolta der I Brigade, eine Atr von Massenselbstmord und so weiter sehen. Wenn auch diese Pläne eine lächerliche Fanfaronade sind, so wäre es trotzdem vorsichtshalber angezeigt, die I Brigade der Legionen unauffällig zu beaufsichtigen.

Es ist Hoffnung vorhanden, dass die Piłsudski - Krise iiberstanden werden wird, trotzdem Pilsudski durch die den Polen eigentümliche Übertreibung zu einem Nationalheros gestempelt wurde. Jedenfalls werden die gemässigten Elemente unter den Polen einen harten Kampf iiberstehen müssen; in diesem Kampfe müssen ihnen die Behörden in vorsichtiger und unauffälliger Weise beistehen. Vom Standpunkte der Presspolitik mïsste der Grundsatz zur Galtung gebracht werden, dass die Angriffe gegen das Oberste Nationalkomitee und dessen Institutionnen, wie das Militärdepartement unterdrückt werden sollen. Eine Sistierung einiger Blätter würde vielleicht im jetzigen Moment böses Blut hervorrufen. Vielleicht wäre jedoch am Platze, dass Verbot der Verbreitung von Blättern wie "Głos Narodu" und „Kurier Codzienny” im k.u.k. Okkupationsgebirt anzuordnen und eine diesbezügliche Weisung an das Pressbureau des k.u.k. Militärgeneralgouvernements in Lublin gelangen zu lassen. Eine strenge Beaufsichtigung der Lubliner Presse wäre auch am Platz.

Brak podpisu

Kopia, maszynopis.

Haus - Hof - und Staatsachiv, Krieg, PA I, karton 1025, plik $\alpha$, folium 134-137.

18 Chodzi o wybitnych piłsudczyków Michała Sokolnickiego i Leona Wasilewskiego. 


\section{Dokument nr 12}

1916 październik 6, Warszawa. - Rozszyfrowana depesza barona Leopolda Andriana do austro-węierskiego Ministerstwa Spraw Zagranicznych o podziękowaniach złożonych na jego ręce przez prezesa proaustriackiej Ligi Państwowości Polskiej za przemianowanie Legionów Polskich na Polski Korpus Positkowy.

Vertraulich. Gestern kam ein vom abwesenden Präsidenten der Liga der Staatlichkeit (der stärksten und bekanntlichen austrophilen Partei) bevollmächtigter Delegierter zu mir mit dem Texte einer Dankadresse an Seine k.u.k. Apostolische Majestät, die der Klub anlässlich der Errichtung des polnischen Hilfskorps votiert hat. Auf die Bitte, deren Beförderung zu iibernehmen, erwiderte ich, dass ich die Adresse zunächst Euer Exzellenz vorlegen würde. Dieselbe wird nach entsprechender Ausfertigung und Anfertigung einer deutschen Übersetzung voraussichtlich bis zum Sonntagskurier fertig sein.

Der Adresse kommt insoferne Bedeutung zu, als sie die erste Kundgebung einer nahmhaften und angesehenen Partei im Königreiche Polen für eine der Mittelmächte respektive deren Herrscher ist. Widerholte Bemühungen der Deutschen, eine derartige Manifestation für Seine Majestät Kaiser Wilhelm zu organisieren, sind stets bereits in den ersten Anfängen gescheitert.

An Anbetracht angeführter Umstände würde ich sehr danbar sein, wenn ich in die Lage versetzt würde, seinerzeit der leitung der Staatlichkeits - Liga eine entsprechendde Antwort zukommen lassen zu können.

Kopia, maszynopis.

Haus - Hof - und Staatsarchiv, Krieg, PA I, karton 901, plik Oktober 1916, str. 26.

\section{Dokument nr 13}

1916 październik 8, Cieszyn. - Raport przedstawiciela austr-wegierskieno Ministerstwa Spraw Zagranicznych w kwaterze Naczelnej Komendy A, austro-wegierskiej dla ministra Stefana Buriana.

Wie ich in streng vertraulicher Weise auf Umwegen höre, hat sich die Nachricht ïber die Demmission Piłsudskis und insbesodere über den hie- 
bei von deutscher Seite auf uns uns ausgeïbten Druck rasch in deutschen Okkupationsgebiete Polens verbreitet und dort recht unliebsames Aufsehen erregt.

Das deutsche Gouvernement in Warschau scheint nun den Wunsch zu haben; diese Mißstimmungen zu besänftigen, und wohl auch einen Teil der Verantwortung für die Annahme der Demission Piłsudskis auf uns abwälzen zu wollen. Damit dürfte es sich erklären, dass die deutsche Oberste Heeresleitung auf einen Wunsch des Warschauer Gouverneurs hin beim Armeeoberkommando das Ersuchen gestellt hat, durch eine kurze Zeitungsnotiz, die bei uns und in Deutschland zu erscheinen hätte, die Nachricht zu lancieren, dass Oberst - Brigadier Piłsudski dem Armeeoberkommando seine Demission angeboten und dass dieses die Demission angenommen habe.

Wie ich höre, hat sich zunächst Oberst von Hranilović dagegen ausgesprochen, diesen Wunsch zu erfüllen. Er stellt sich hiebei auf den Standpunkt, dass zunächstsachlich kein Anlass vorhanden ist, jetzt mit einer Press - Enunziation hervorzutreten, nachdem man dies im Zeitpunkte der Annahme der Demission Pilsudskis nicht getan hatte. Abgsehen hievon entspreche es gar nicht unseren Interessen, durch eine solche offizielle Pressnachricht die Situation der Deutschen gegenüber den polnischen Kreisen zu erleichtern, da es uns nur erwïnscht seine könne, wenn in Sinne der tatsächtlichen Verhältnisse unter den Polen die Nachricht unvermindert weiter kursiert, dass die Annahme der Demission Piłsudskis in erster Linie auf einen von deutscher Seite ausgeübten Druck zurückzufüren ist, dies umsomehr, da man in den polnischen Kreisen ganz genau weiss „dass die Schaffung des polnischen Hilfskorps zu Differenzen mit der deutschen Regierung geführt hat.

Hievon glaube ich, Ihnen, hochgeehrter Herr Minister, Mitteilung machen zu sollen, da die Angelegenheit durch diese Stellungsnahme des Obersten von Hranilović nicht erledigt sein dïrfte und man wohl noch an den Chef des Generalstabes appelieren wird.

Jedenfalls habe ich, soweit es mir bei der ganz vertraulichen Art der Kenntnisnahme dieses Vorganges möglich war, getrachtet, dahin zu wirken, dass eine Entscheidung nicht ohne vorheriges Einvernehmen mit uns getroffen wird. Inwieweit dies gelungen ist, kann ich nicht beurteilen, weshalb ich mir für alle Fälle anzuregen erlaube, dass uns ein telegraphischer Erlass zugehe, der etwa folgenden Inhalt hätte:

"Wie ich vertraulich erfahre, wïnscht die deutsche Oberste Heeresleitung die Publizierung einer kurzen Notiz ïber die Demission Piłsudskis im obigen Sinne. Ich ersuche Euer [Exzellenz] in dieser Frage meinen 
Standpunkt dem Armeeoberkommando gegeniiber in nastehender Weise zu präzisieren..." 19

Wie ich beifügen darf, scheint mir die Stellungnahme des Obersten von Hranilović der Situation vollkommen zu entsprechen.

Genehmigen Sie, hochgeehrter Herr Minister, den Ausdruck meiner Verehrung und Ergebenheit.

Podpisał Wiesner

Telegram, maszynopis.

Haus - Hof - und Staatsarchiv, Krieg, PA I, karton 901, plik Oktober, folium $35-36$.

\section{Dokument nr 14}

1916 październik 9, Cieszyn. - Przedstawiciel austro-wegierskiego Ministerstwa Spraw Zagranicznych w kwaterze austro-wegierskiej Naczelnej Komendy Armii do ministra spraw zagranicznych w sprawie dotyczacej usunięcia putkownika Kazimierza Sosnkowskiego z Legionów Polskich.

In der Anlage beehre ich mich, eine streng geheime Note des k.u.k. Armeeoberkommando an das k.u.k. Ministerium des Äussern, betreffend die Entlassung des Legionsobersten Sosnkowski aus den Polnischen Legionen, samt einer Beilage zu unterbreiten.

Podpisał F. Kinsky

\section{Zatacznik nr 1}

Cieszyn, am 6 Oktober 1916.

Dass Armeoberkommando beehrt sich in der Anlage eine Abschrift des an den Lagionsobersten Kasimir von Sosnkowski gerichteten Befehles zu iibermitteln, in welchem demselben die von ihm erbetene Entlassung aus dem Verbande der Polnischen Legionen genehmigt wird.

19 Tak w tekście. 
Diese Entlassung ist eine Konsequenz der Demission Piłsudskis und ergab sich mit zwingender Notwendigkeit aus dem Umstande, dass der genannte Legionsoberst, als Stabs-chef und Stellvertreter Piłsudskis vollkommen in dessen Intensionen gehandelt hat und auch weiterhin diese zersetzende Tätigkeit in der Legion fortgesetzt hätte. Die Belassung Sosnkowskis in der Legion hätte ebenso wie jene Piłsudskis den Bestand der ernstlichen gefährdet.

Die Denkungsweise Sosnkowskis geht auch aus seinem Demissionsgesuch hervor, in dem er betont, dass die Anwesenheit Piłsudskis in der Legion für ihm wie für alle anderen, aus dem Königreiche Polen stammenden Offiziere und Soldaten als einzige Bürgschaft galt, dass sie nicht nur als Lohnsoldaten, gewissermassen als moderne Condottieri, am jetzigen Weltkriege teilnehmen.

Anlässlich der Entlassung des Sosnkowski wurden analoge Massnahmen für die Pressezensur und zur Verhinderung einer agitatorischen Tätigkeit getroffen wie bei der Enlassung Piłsudskis.

\section{Zatacznik nr 2}

Armeeoberkommando K. Nr 21032.

Entlassung des Legionsobesrst Sosnkowski aus den Polnischen Legionen in Sandomierz.

[Cieszyn], am 6 Oktober 1916.

Das Armeeoberkommando sieht sich veranlasst, in Stattgebung Ihrer Bitte vom 3 Oktober leitendes Jahres Ihre Entlassung aus dem Verbande der Polnischen Legionen zu verfügen.

Das Armeeoberkommando bedauert in Hinblick auf die militärischen Leistungen Euer Hochwohlgeboren als Regimentskommandant und Stellvertreter des Brigadiers, Euer Hochwohlgeboren nach mehr als zweijähriger Tätigkeit von Ihre militärische Verdienste seine vollste Anerkennung aus. 


\section{Dokument nr 15}

1916 październik 9, Wiedeń. - Polecenie austro-węierskiego ministra spraw zagranicznych dla sekretarza sekcji „kawalera” von Wiesnera w sprawie opublikowanego oświadczenia dotyczącego Legionów Polskich.

Der kaiserlicher deutsche Botschafter hat mit einer dem Armeeoberkommando mit Note vom 29 vorigen Monats Nr 4802 mitgeteilten Notiz anher bakanntgegeben, dass die deutsche Oberste Heeresleitung den Wunsch geäussert habe, dass ihr durch die auf die Polnischen Legionen Bezug habende bekannte Kundmachung des Armeeobrkommandos angäblich stark erschïttertes Prestige durch eine unsererseits zu erlassnde, entsprechende, öffentliche Erklärung wieder hergestellt werde.

Wenn ich auch nicht recht habe einsehen können, inwieweit das deutsche Ansehen in Polen durch die Verfügung des Armeeoberkommandos hat tangiert werden können, so habe ich doch dem Wunsche des Feldmaschalls vo Hindenburg Rechnung tragen wollen und habe mich in meiner dem Herrn von Tschirschky gegebenen Antwort im gewïnschten Sinne in Erwägung zu ziehen.

Ich beehre mich nunmehr den Entwurf eines diesbezüglichen Communiqués Euer Hochwohlgeboren zu übermitteln mit dem Ersuchen, denselben dem Herrn Generalstabschef zur Kenntnis bringen und umgehend anher berichten zu wollen, ob das Armeeoberkommando mit der Veröffentlichung desselben sich einverstanden erklärt.

Kopia wysłanego pisma; podpisu nie ma

\section{Zatacznik}

Projekt pisma dotyczqcego irytacji Niemiec w zwiqzku z przemianowaniem Legionów Polskich na Polski Korpus Positkowy.

Die bekannte Kundmachung des k.u.k. Armeekommandoos ïber die Umbenennung der Polnischen Legion zu einem wie bisher im Verbande der k.u.k. Armee kämpfenden Hilfskorps hat vielfach eine irrige Deutung erfahren. Infolgedessen sei festgestellt, dass das bisherige Wesen der Legion in keiner Weise durch den Umstand berïhrt worden ist, dass als berechtigt erkannten nationalen Wiinschen Rechnung getragen und gleichzeitig 
den Legione eine wohlverdienste Belohnung und Anerkennung ihres tapferen Verhalten im Kriege zuteil wurde.

Alle darüber hinausgehenden Folgerunggen sind gegenstandslos, solange die Geschicke Polens noch unentschieden sind. In der Zwischenzeit werden Österrich - Ungarn und Deutschland nach wie vor sich bemïhen, in treuer Bundesgenossenschaft und in vollem Einvernehmen die polnische Frage einer allen Anforderungen der tatsächlichen Verhältnisse gerecht wernenden und befriedigenden Lösung gemeinsam zuzuführen.

Projekt pisma przygotowywanego w austro-węgierskim Ministerstwie Spraw Zagranicznych; podpisu nie ma.

\section{Dokument nr 16}

1916 październik 10, Berlin. - Nota austro-wegierskiego ambasadora w Berlinie dotyczqca nowego uregulowania warunków przejazdu legionistów polskich przez terytorium Niemiec.

Der hiesige Stellvertretende Gross Generalstab hat seinerzeit die Aumerksamkeit des k.u.k. Arme - Oberkommandos auf den Umstand gelenkt, dass der russische Nachrichten-dienst in Kopenhagen alle Mittel aufbiete, um die dort weilenden auf ihre Einrückung wartenden polnische Legionäre für ihre Zwecke zu gewinnen und häufig auf die Weise ihre Spione nach Österreich - Ungarn einschmuggele.

Diesem Überstande ist seinerzeit dadurch teilweise gesteuert worden, dass die Legionäre nur nach Erhalt eines Offenen Befehls seitens des Polnischen Nationalkomitees ihre Reise nach Österreich - Ungarn antreten durften und dass die Durchreisebewilligung durch Deutschland nur für solche Personen erwirkt worden ist, welche mit dieser ebenerwähnten Legitimation versehen waren.

Immerhin hat der deutsche Generalstab die Wahrnehmung gemacht, dass die polnischen Legionäre, die wochenlang in Kopenhagen verbleiben müssen, bis sie die Bewilligung zur Durchreise durch Deutschland und Einreise in die Monarchie erhielten, seitens der russischen Emissäre in einen für uns höchst unerwïnschten Sinne beeinflusst wurden.

Der Stellvertretende Generalstab hat das k.u.k. Armee - Oberkommando auf diese Übelstände aufmerksam und gleichzeitig folgende Vorschlagen gemacht: 
Die in Kopenhagen eintretenden Legionäre sollen unverzïglich beim hiesigen Stellveretenden Generalstab gemeldet werden, worauf diese letztere Stelle die Grenzpolizeibehörden in Sassnitz anweisen wird, die Legionäre, welche nunmehr nach Sassnitz und nicht mehr nach Warnemïnde instradiert werden, zu iibernehmen. Hier werden die Legionäreunter Ansicht unserer dortigen Militärstelle - derziet ist k.u.k. Oberstleutnant Alois Czulik zur Übernahme unserer aus Russland kommenden Austauschverwundeten hinkommandierte - interniert, bis unsere Militärstellen denselben den Befehl zur Weiterreise in die Monarchie zukommen lassen.

Durch dieses Verfahren wïrde einerseits längerer unerwiinschter Aufenthalt der Legionär in Kopenhagen vermieden und anderseits auch dem fast gleichzeitig mit der gedachten Anregung des deutschen Generalstabes vorgebrachten Wunsche unseres Armee-Oberkommandos, die Legionäre nahe der dänischen Grenze in einem deutschen Orte unterzubringen Rechnung getragen werden.

Da bezüglich der Regelung dieser Frage zwischen unseren un den deutschen militä rischen Stellen keine Meinungsverschiedenheiten bestehen, hat der hiesige Stelvertretende Generalstab diese k.u.k. Botschaft ersucht, die k.u.k. Gesandtschaft in Kopenhagen schon vor dem formellen Abschluss des diesbezïglichen Übereinkommens von diesenm neuen Verfahren in Kenntnis zu setzen, welchem Wunsche die k.u.k. Botschaft bereits unter Einem entspricht.

In Hinkunft hätte die k.u.k. Gesandschaft in Kopenhagen nur das Nationale und die Phographien der dort eingetroffenen Legionäre anherzusenden, worauf die k.u.k. Botschaft nach vollzogener Anmeldung beim Stellvertretnden Generalstabe die gedachte k.u.k. Gesandschaft verständigen wïrde, dass die Legionäre die Reise antreten dürfen. Diese würden nun einen Offenen Befehl seitens unserer Gesandschaft und einen Sichtvermerk von dortigen deutschen Gesandschaft (oder deutschen Generalkonsulat) erhalten und wïrden von den bereits seitens der hiesigen Stellvertretenden Genralstabes entsprechend angewiesenen deutschen Grenzstellen in Sassnitz iibernommen und dort interniert werden. (Die Instra-dierung der Legonäre iiber Warnemünde ist aus militärischen Gründen nicht möglich).

Der Stellvertretende Generalstab ist mit dem Voschlage an diese k.u.k. Botschaft herangetreten, es möchte in Hinkunft - um Zeit zu gewinnen die Einreisebewilligung der Legionäre nach Deutschland direkt beim Generalstab selbs - also unter Ausschaltung des Auswartigen Amtes - erwirkt werden. Dies wiirde allerdings die Erledigung der baziiglichen Angelenheiten bedeutend beschleunigen, doch hat die k.u.k. Botschaft diese Anregung 
der gedachten deutschen Militärstelle vorläufig im Auswärtigen Amte noch nicht zur Sprache gebracht.

Einer geneigsten Weisung über diesen letzten Punkt darf die k.u.k. Botschaft ergebenst entgegensehen.

Der k.u.k. Geschäftsträger: [Larisch]

Kopia, maszynopis.

Haus - Hof und - Staatsarchiv Krieg, PA I, karton 901, plik 8a, folium 178-179.

\section{Dokument nr 17}

1916 październik 11, Wiedeń. - Pismo przewodnie szefa Biura Prezydialnego NKN do austro-węgierskiego Ministerstwa Spraw Zagranicznych i dwa zataczniki.

Im Auftrage des Vizepräsidenten des Obersten Polnischen Nationalkomitees Herrn prof. von Jaworski erlaube mir Euer Exzellenz den Inhalt des von Herrn Dr von Jaworski an den Brigadier Piłsudski gerichteteten Schreibens, wie auch der Antwort des Letzteren in Übersetzung zur geooffentliche Kenntnis zu bringen. Mit der Versicherung vorzüglichster Hochachtung bin ich Euer Exzellenz ganz ergebener.

Podpis nieczytelny

Oryginał, maszynopis.

Haus - Hof - und Staatsarchiv, Krieg, PA I, karton 901, plik 8a, s. 180-183.

\section{Zatacznik nr 1}

Pismo wiceprezesa NKN Leopolda Jaworskiego do brygadiera Józefa Pitsudskiego z 5 października 1916 r. w zwiazku z jego dymisja ${ }^{20}$.

20 Pismo to nie zostało podane do druku, ponieważ jest to tłumaczenie polskiego dokumentu: por.: Dokumenty Naczelnego Komitetu Narodowego 1914-1917, Kraków 1917, s. 299-301. 


\section{Zatacznik nr 2}

Odpowiedź brygadiera Józefa Pitsudskiego na pismo profesora Leopolda Jaworskiego z 6 października 1916 r. ${ }^{21}$

\section{Dokument nr 18}

1916 październik 12, Cieszyn. - Pismo szefa sztabu armii austro-węgierskiej generała Franza Conrada von Hötzendorfa do austro-węierskiego ministra spraw zagranicznych barona Stefana Buriana von Rajecz w sprawie Legionów Polskich w Baranowiczach.

Euer Exzellenz beehre ich mich nachstehenden Vorfall betreffend die Polnische Legionen zu informieren.

Ich wurde am 5 Oktober leitendes Jahres vom k.u.k. Verbindungsoffizir beim Ober-kommando Ost in Kenntnis gesetzt, dass von diesem Kommando das Herausziehen der Polnischen Legionen aus front zwecks Abbeförderung nach Baranowiczi verfügt wurde.

Durch Herauziehen der Polnischen Legionen wurde allerdings eine Wunsche des AOK nach Retablierung derselben entsprochen, doch musste ich Seiner Exzellenz General Feld-marschall von Hindenburg darauf aufmerksam machen, dass in dieser Frage das Einverne-hmen mit dem AOK herzustellen gewesen wäre und dass die Unterstellung der Polnischen Legionen unter eine k.u.k. Kommandostelle im Hinblick auf die inneren Verhältnisse der Polnischen Legionen geboten erscheint.

In der Zwischenzeit traf General Major von Puchalski, der Kommandant der Polnischen Legionen beim AOK ein und berichtete ïber die Wirkung, welche das ganz ïberraschende Vorgehen der deutschen Obersten Heeresleitung ausgelöst hat.

Dies veranlasst mich nunmehr das in Abschrift beiliegende Schreiben an General Feldmarschall von Hindenburg zu richten. 


\section{Zatacznik}

Zataczone pismo generata Franza Conrada von Hötzendorfa do feldmarszatka Pawta von Hindenburga. Cieszyn, 12 października 1916.

Auf mein am 5 Oktober gestelltes Ersuchen Op. Nr 31598 betreffs Unterstellung der Polnischen Legionen unter ein k.u.k. Kommando habe ich zu meinem Bedauern noch keine Antwort erhalten, hingegen meldet mir der Kommandant der Polnischen Legionen General Major von Puchalski, dass er durch die Verlegung nach Baranowiczi geradezu überrascht wurde und bis zum letzten Augenblick über das Ziel der Verlegung nicht orientiert war.

Bei der dem AOK wohlbekannten inneren Struktur der Polnischen Legionen war vorzusehen, dass eine solche Massregel in den Legionen auch unter normalen Verhältnissen Unruhen erzeugen und $\mathrm{zu}$ verschiedenartigen Gerüchten Anlass bieten musste. Das sich aber gegenwärtig die Polnischen Legionen in einem durch die Entlassung Piłsudskis hervorgerufenen krisenhaften Zustand befinden, ist für den Kenner der Verhältnisse nicht überraschend, dass die von der Obersten Heeresleitung getroffene Massregel bei den Polnischen Legionen eine besondere Erregung hervorgerufen hat, welche für die agitatorische Tätigkeit der sozialistischen Partei und aller Anhänger Piłsudskis den besten Nährboden abgibt, den inneren Gehalt der Polnischen Legionen gefährdet, ja direkt den Bestand dieser der Österreich - Ungarrische Wehrmacht angehörenden Formationen in Frage stellen kann. Tatsächlich sind bereits Massengesuche von Offiziere und Mannschaft der Polnischen Legionen zum Entlassung eingelaufen.

Ich kann nur mit aufrichtigen Bedauern diese die gemeinsamen Interessen schwer schädigende Wirkung der auch für das AOK vollkommen überraschend gekommenen Massregel der Obersten Heeresleitung konstetieren.

In den begeisterungsfähigen und kampfbereiten Schichten der polnischen Bevölkerung wird sich leider der Eindruck dieses Vorgehens nicht leicht wieder gut machen lassen, was umso bedauerlicher ist, als hiedurch das im polnischen Volk bestehende Misstrauen gegen die Absichten der Zentralmächte gerade im ungünstigsten Momente neu belebt wird.

Es dürfte der Aufmerksamkeit der Obersten Heeresleitung wohl nicht entgangen sein, dass sich dieses Misstrauen in erster Linie gegen Deutschland richtet und es ist daher begreiflich, dass - wie der Kommandant der Polnischen Legionen meldet - schon die blosse Nachricht, dass die Polnische Legionen selbst auf kurze Zeit unter unmittelbare Obhut der Deutschen 
kommen soll, unter den Soldaten den denkbar ungünstigeen Eindruck hervorrief.

Über die Verhältnisse und Stimmungen der Polnischen Legionen vollkommen, orientiert hätte ich, wenn die Oberste Heeresleitung sich bezüglich ihres Vorgehens mit dem AOK ins Einvernehmen gesetzt hätte, Euer Exzellenz zweifellos iiber die Konsequenzen eines derartigen Schrittes im Vorhinein aufklären können und durch diesen bedauerlichen Schritt verhindert.

General Major von Puchalski meldet mir aber auch gleichzeitig, dass von Generalstabschef des Oberkommandos Ost am 3 September leitenden Jahres eine Besprechung mit dem Kommandanten der Polnischen Legionen unter Beiziehung eines Legions - Obersten eingeleitet wurde, die dem Sinne nach darauf abzielte, ob unsere Legionsoffiziere bereit wären in deutsche Dienste zu treten und an der Bildung deutscher polnischer Legionen sich zu beteiligen.

Ich glaube annehmen zu können, dass Euer Exzellenz mein Urteil über dieses Vorgehen begreifen und wäre ausserordentlich dankbar gewesen, wenn Euer Exzellenz sich in dieser Frage an mich gewendet hätten.Euer Exzellenz hätten auf mein bereitwilligstes Entgegenkommen gewiss rechnen können, wenn ich ïber die Absichten Euer Exzellenz orientiert gewesen wäre.

Ich bitte schliesslich dringend die Polnische Legionen, welche ohne $\mathrm{Zu}$ stimmung und wie ich auf Grund der mir jetzt bekannten Sachlage erklären muss auch gegen den Willen des AOK sich in Baranowiczi befinden, über Brest Litowsk in den Bereich des k.u.k. Verwaltungsgebietes abzusenden, wo ihre Retablierung, ihre Ergänzug und die Fortsetzung ihres Ausbildung im wohlverstandenen Interesse der gemeinsamen Sache vorteilhaft bewirkt werden kann.

Podpis: Conrad Generaloberst

\section{Dokument nr 19}

1916 październik 18, Cieszyn. - Pismo austro-wegierskiego szefa Sztabu Generalnego Franza Conrada von Hötzendorfa do ministra spraw zagranicznych Stefana Buriana z prośba o wyjaśnienie zamiarów dotyczacych rozwiazania sprawy polskiej.

Beiliegend beehre ich mich, Euer Exzellenz eine eben eingelangte Meldung des k.u.k. Verbindugsoffiziers beim Heeresgruppenkommando General 
Oberst von Woyrsch, in deren Bereich sich die Polnische Legion derzeit befindet, zur gefälligen Kenntnis zu iibermitteln.

Aus dieser Meldun wollen Eure Exzellenz zunächst ersehen, dass das Ausbleiben der von den Polen erwarteten Deklaration der Zentrallmächte über die Zukunft Polens Ursache der Anschauung ist, dass Euer Exzellenz unser Désinteressement in der polnischen Frage erklärt hätten ${ }^{22}$. Obwohl mir iiber eine solche Erklärung nichts bekannt geworden ist, scheint dies aus der Krakauer Emanation Herrn von Biliński's geschlossen zu werden und hat die sehr bedenkliche Bewegung in der Polnischen Legion - trotz der ihr erst jüngst gemachten militärischen Zugeständnisse - ausgelöst, die deren weiteren Bestand in Frage stellt.

Welche Folgen ein, ihrer Auflösung gleichzuhaltender Massenaustritt polnischen Legionäre und ihrer Offiziere aus dem Legionsverbande in politischer und militärischer Hinsicht haben könnte, ist wohl klar. Abgesehen von dem militärischen Kraftverluste, wïrde die Auflösung der Polnischen Legion nicht nur unsere politische Stellung gegnüber den Polen Österreichs und Kongresspolens, sondern auch dem Deutschen Reiche und dem feindlichen und neutralen Auslande gegenüber unheilbar kompromittieren. Das gleiche Ergebnis für uns müsste eintreten und die Aufösung der jetzigen Polnischen Legion nach sich ziehen, sobald der schon jetzt zu Tage tretende Zweifel an unserer Unterstiitzung der Polen weiter Boden gewinnt und erkannt wird, dass die Führung der ponischen Wehrkraft ausschliesslich in deutsche Hände gelegt worden soll.

Für eine von den Deutschen allein organisierte und geführte polnische Armee werden - wie auch der zuliegende Bericht zeigt - die Polen nicht viel übrig haben.

Schiesslich würde uns die Auflösung der Polnischen Legionen des einzigen Kader's für die Aufstellung und Ausbildung eines polnischen Heeres barauben, die Schaffung eines solchen also von Haus aus unmöglich machen.

Gegen all' diese bedenklichen Folgen für unsere Zukunft und unser Prestige gibt es, meines Erachtens, nur ein Mittel: das in der allernächsten Zeit unerlässliche Erscheinen der Deklaration der Zentralmächte ïber die Zukunft Polens, deren Formulierung und ungesäumte Ausgabe ich Euer Exzellenz in der am 18 dieses Monats in Pless stattfindenden Konferenz mit allen Mitteln anzustreben bitte.

22 Na marginesie pisma znajduje się odręczna uwaga sporządzona najprawdopodobniej przez ministra Buriana: „Ich habe das genaue Gegenteil erklärt”. 
Genehmigen Euer Exzellenz den Ausdruck meiner ausgezeichneten Hochachtung.

Podpis: Conrad Generaloberst

Oryginał, maszynopis.

Haus - Hof - und Staatsarchiv, Krieg, PA I, karton 901, plik Oktober 1916, folium 199.

\section{Zatacznik}

odpis (zawiera meldunek austro-węgierskiego oficera tacznikowego przy dowództwie grupy generata von Woyrscha, nadestany do AOK z 16 października $1916 r$.

Auf Grund einer persönlichen Besprechung mit Oberst Graf Szeptycki, in Beurlabung des Herrn Generals Puchalski, Interimskommandant der Polenlegion, fühle ich mich verpflichtet, folgendes zu melden:

Die Verhältnisse bei der Polnischen Legionen haben sich zu einer ernsten Krise zugespitzt. Hiefürbestehen vor Allem politische Gründe. Dadurch, dass der k.u.k. Minister Äuseren gegenüber der polnische Frage eine Désinteressementtererkaärumg abgab, und dies den polen durch Biliński in Krakau bekanntgemacht wurde, hat sich der Polenlegion eine Niedergeschlagenheit bemächtigt. Ihre politischen Wortführer sagen: „Wir haben 2 Jahre für unsere idealen Ziele gekämpft, das heist für eine Lösung der polnischen Frage im Anschluss an Östrreich. Jetzt erklärt Österreich sein Désinteressement an der polnischen Frage. Dies ist gleichbedeutend mit der Unmöglichkeit, unsere Ziele erreichen. Daher wollen wir nicht weiter kämpfen, sondern bitten um unsere Entlassung".

Diese Bewegung greift immer mehr um sich. Die Galiziener wollen in die k.u.k. Armee eintreten, die aus Russlands Polen starnmenden Legionäre wollen nach Hause.

Bisher haben ungefähr 250 Offiziere und 3000 Mann um ihre Entlassung gebeten. Oberst Graf Szeptycki hat durch seinen Einfluss die Leute soweit gebracht, dass sie eine noch zuwartende Haltung bewahren. Er hat die Entlassungsgesuche bei sich zurückbehalten und leitet sie vorläufig nicht weiter und beschwichtigt die aufgeregten Gemüter. Er sagt, er könne die Leute noch ein - zwei Wochen im Zaum halten, höchstens drei Wochen, aber länger keinesfalls mehr. 
Es würde sich demnach darum handeln, darüber klar zu werden, ob man die Polenlegion erhalten will oder ob man deren sicheren Zerfall vorzieht. Das erste könnte nur durch die politische Erklärung ermöglicht werden, welche den Polen eine Basis gibt, auf welcher sie die künftige Gestaltung Polens in einer für sie gïnstigen Sinne erhoffen könnten.

Könnte dies sich geschehen, so würde in aller kürzester Zeit der Abfall von mindestens zwei Drittel der Legion zu erwrten sein. Dies ist die Ansicht der bei der Legion stehenden österreichisch - unagrische Offiziere.

Verstärkt wurde der Missmut der polnischen Legionäre auch dadurch, dass sie ihre Versetzung nach Baranowitschi zur Heeresgruppe von Woyrsch quasi als eine Internierung deutscherseits betrachten und fürchten, durch die Deutschen in einem ihnen nicht konvenierenden politischen Rahmen gepresst zu werden. Się wollen nicht „travailler pour le roi de Prusse” ${ }^{23}$, nachdem sich Österreich von ihrer Sache zurückzieht.

Naturgemäss ist die Situation unter diesen Umständen für die dort einteilten österreichisch - ungarische Offiziere eine äusserst schwierige. Die Wortführer der Legion fragen: „Was machen die österreichische Offiziere bei der Legion, wenn Österreich, ihr Vaterland, sein Désintereesment erkärt?" Das sei doch unvereinbar!

Bemerken will ich noch, dass die Legionäre entschlossen sind, ihre eventuelle Auflösung bezw[wecken] Entlassung in grösster Ruhezu volziehen, ohne jedwede demonstrative Geste.

Die Polnische Legion ist derzeit im grossen russischen Barackenlager in Baranowitschi und in den umliegenden Ortschaften untergebracht, hat vollkommene Ruhe und ist Reserve der Heeresgruppe. Es wird für sie von Seite der Heeresgruppe in entgegenkommendster Weise gesorgt.

Als k.u.k. Verbindungsoffizier fühle ich mich verpflichtet, ïber Zustände bei der Polnischen Legion umgehend Meldung zu erstatten und die Aufmerksamkeit des Armeeoberkommandos auf die brennende Krise bei der Legion zu lenken.

Odpis, maszynopis, brak podpisu.

23 Tu chodzi o znane określenie polityczne: „Pracować dla pruskiego króla”. A więc dla Prus. 


\section{Dokument nr 20}

1916 październik 19, Cieszyn. - Pismo przedstawiciela austro-wegierskiego Ministerstwa Spraw Zagranicznych w kwaterze austro-węgierskiej Naczelnej Komendy Armii do ministra Stefana Buriana w sprawie dotyczqcej zwolnienia Józefa Pitsudskiego z Legionów Polskich.

In der Anlage beehre ich mich, Euer Exzellenz Abschrift eines Berichtes der k.u.k. Generalstabsabteilung der Festung Krakau vorzulegen, welcher zu Ehren Piłsudskis in Krakau abgehalten Abschiedsfeierlichkeiten schildert.

Podpisał: Wiesner

\section{Zatacznik do pisma Wiesnera}

(An die Nachrichtenabteilung des k.u.k. AOK. Krakau, am 10 Oktober 1916).

Die Abschiedsfeier Piłsudskis hat am Sonntag vormittags, den 8 dieses Monats im Saale der Ärztegesellschaft stattgefunden. Es wurde eine Adresse mit 50000 Unterschriften, ferner eine goldene Medaille dem gewesenen Brigadier ïberricht. Piłsudski dankte für die Ehrung und hob hervor, dass er den Polen, die Macht der Waffen zu glauben aufgehört haben, den polnischen Soldaten wieder geschaffen hat. Es ist jedoch Sache der ganzen Gesellschaft, des ganzen Vaterlandes, an der Unabhängigkeit Polen zu arbeiten.

Abends hat ein Festessen im Hotel „Poller” stattgefunden, an dem zirka 150 eingelade'ne Personen teilgenommen haben, darunter die Abgeordneten Daszyński, Klemensiewicz, Marek, Śliwiński, ferner Redakteur Laskowiescki aus Lemberg, Minkiewicz aus Olkusz, Długoszowski gewesene Odonanz Offizier des Piłsudski, eine ganze Reihe von Offizieren der ersten Brigade, von Frauen: die Vorsitzende der Frauenliga Krzyżanowska und Golińska - Daszyńska.

Reden wurden gehalten vom Abgeordneten Daszyński, Redakteur Laskowiecki und Golińska-Daszyńska.

Daszyński hob in seiner Ansprache hervor, dass nach dem Kriege eine grosse Demokratiesirung der Gesellschaften vor sich gehen werde. Die Träger dieser Demokratiesirung werden die heim kehrenden Krieger sein, die in dem grossen Völkerringen sich ïberzeugt haben, welche angeheuren Aufgaben die 
akkumulierte, menschliche Energie zu lösen imstande się. Auch Polen wird in diesem Prozesse der fortschreitenden Demokratisierung nicht hinter den andern Völkern zurückbleiben, und zwei'felsohne dank Pilsudskis,. Auf die politische Lage übergehend, charaktrisierte er die bisherigen Kämpfe um die Unabhängigkeit Polens. Sie seien jedoch noch nicht abgeschlossen, da „ich alles geben werde, wenn Du alles gibst". Er hob die Unaufrichtigkeit und schwachende Haltung der Wiener Regierung den Polen gegenïber, selbst dem Angebote des OPNK gegenüber, das sich für einen engen Anschluss Polens an die Monarchie, auf ähnlicher Basis wie Ungarn, ausgesprochen hat hervor. Diese Schwäche, Unaufrichtigkeit und Unfähigkeit der Regierung wurde von einer Seite ausgenützt, von de man es am allerwenigsten erwartet hätte, das ist von Preussen, welches direkt eine Bauernfängerei betreibt durch allerei gezahlte, un geheime Agenten. Dieser Mangel an Entschlossenheit und einheitlicher politischer Richtung, den die Regierung zeigt, hat zur Folge, dass das polnische Volk von eimem Extrem ins andere verfällt. Es darf nicht übersehen werden, dass die Russen bei ihrem Rïckzuge aus Polen eine ganze Meute von Agenten zurïckgelassen haben, die jeden ungeschickten Schritt der österreichisch - ugarische Regierung ausnïtzen. Zum Gliick haben sich Leute unter den polnischen Beamten gefunden, die ihre amtlicheen Pflichten mit den allgemeinmenschlichen zu koordinieren verstanden haben. Dies hatte zur Folge, dass die ursprünglich russophilen Gouvernements, das ist Radom und Piotrków den grössten Rekrutenkontingent für die Legionen gestellt haben und dass die Bevölkerung dieser Kreise am meisten und aufrichtig mit der Verwaltung zufrieden ist. „Mit dem ersten besten Zugeständnis lassen wir uns nicht abfertigen. Gegen̈̈ber dem Vowurfe, dass die Polen nur ihre Pflicht getan, muss mit allen Nachdrucke hervorgehoben werden, dass sie mehr als ihre Pflicht getan haben. Auch die Czechen haben ihre Pflicht getan, aber wie, das wissen wir alle. Ihre Pflicht haben auch andere Nationen getan, aber wie, dass wissen wir auch". Das eine muss hervorgehoben werden, dass keinpolnischer Soldat sich ergeben hat, wenn er dazu nicht durch Sperrfeuer gezwungen war. Nicht in der Tatsache, dass sie ihre Pflicht getan, sondern in der Art., wie sie es getan haben, liegt die Kraft und das recht der Polen, ihre Forderungen offen stellen zu können. Er schloss mit den Worten: „Du hast die Seele Polens aus ihren Schlafe geweckt und hast den Typus nich eine Condottiere, sondern eines Soldaten geschaffen der für die Idee sein Leben gibt".

Andere Reden sind bedeutungslos. Frau Golińska-Daszyńska sprach, dass selbst die Frauen zu den Waffen greifen werden, wenn es nötig sein solle. 
Zum Scluss sprach Piłsudski. Er führte aus, er sei dankbar allen denjenigen in Galizien, die ihm die Waffen in die Hand gedrïckt haben, da er ohne ihre Hilfe keine Soldaten hätte schaffen können und die ganze Bewegung wäre nur ein Guerillakrieg, wie im Jahre 1863. Als Soldat könne er keine Politik machen; dazu seien się leute im Hinterlande berufen. Wenn die Politiker nicht imstande waren, oder es sind, das zu erreichen, was das Volk von ihnen verlange, so könne er unter diesen Verhältnissen nicht arbeiten und wird erst dann zurïckkehren, wenn sich der Horizont geklärt hat und er durch massgebende Faktoren wieder berufen wird, Das, was gegenwärtig existiert, muss als Kern der zukünftigen Amee durchhalten. Persönlichen Ehrgeiz hatte er nie, wenn aber die Nation ihm zum Obersten Feldherrn und Schöpfer der Legionen ernennt, so muss er hiefür die Verantwortung ïbernehmen, und wenn dieselbe seine Kräfte iibersteigt, so muss er sich zurïckziehen. Er hat nicht die Brïcken hinter sich abgebrochen, wiewohl das gar manchen Faktoren sehr genehm wäre. Dazu wird es nicht kommen. Der Krieg hat die Polen kïhl zu urteilen gelehrt und hat nochmals den Spruch bekräftigt: Timeo Danaos et dona ferentes (die Preussen). Es ist die Pflicht der Politiker, die Sachlage zu klären: „Wieviel und wofiir?” Seine Pflicht ist es, wenn die Zeit gekommen sein wird, dort sich einzufinden, wo er am 6 August 1914 war. Davon wird er trotz Bitterkeit und trotz aller Vorkommnisse, denen er ausgesetzt war, nicht zurïckschrecken.

Im "Naprzód” war dieser Teil Rede nicht reproduziert. Dem Blatte (Nr 281) ist Folgendes zu entnehmen: Pilsudski hob hervor, er sei Soldat und wolle keine Politik machen. Dazu seien Leute hinter der Front. Wenn er in die Vergangenheit bis zum 6 August 1914 zurïblikt, so zieht er, dass die Nation nicht jene Kraft gezeigt habe, die nötig war. Der polnische Soldat war für das Volk ein Mythus, an seine Realität wollte oder konnte man nicht glauben. Die Nation stehe vor äusserst wichtigen Entscheidungen und miisse ihre ganze nverfügbaren Kräfte, die sehr gross seien, und die in Anbetracht der allgemeinen Erschöpfung nur an Wert gewinnen werden, zu sammeln un zu konsolidieren trachten. Wenn nach dem Kriege die allgemeine Abrechnung erfolgt, wird einem jeden nach seinem Werte zuerkannt werden. Es wird alles auf sehr empfindlichen Wagen abgewogen werden. Das Volk müsse daher vorbereitet sein und zeigen, ïber welche moralische Kräfte es verfügt. Er schloss:" Der polnische vaterlandslose Soldat möge auch sein Vaterland finden". 


\section{Dokument nr 21}

1916 październik 20, Cieszyn. - Pismo przedstawiciela austro-wegierskiego Ministerstwa Spraw Zagranicznych w kwaterze austro-wegierskiej Naczelnej Komendy Armii do ministra spraw zagranicznych w sprawie dotyczacej powotania w Krakowie Archiwum Legionów Polskich.

Dem k.u.k. Ministrium des Äussern zur Kenntnisnahme des Abschrift beiliegenden Befehles des k.u.k. Armeeoberkommandos betreffend Errichtung eines Polnischen Legions-archivs in Krakau.

Podpisał: [Dionizy] Thurn

\section{Załacznik}

- Dotyczy sprawy archiwum Legionów Polskich w Krakowie.

Das AOK hat dem vom Kommando der Polnischen legionen im Einvernehmen mit dem Kriegsarchiv gestellten Antrage zur Errichtung eines „Legionsarchivs" zugestimmt und verfügt hiezu:

In Krakau ist auf Kriegsdauer ein "Legionsarchiv" als Akten - und Bildersammelstelle für das Polnische Hilfskorps zu errichten, welchem die Sammlung und Sichtung der Feldakten obliegt.

Legionsleutnant Dr Hans Effenberger - Śliwiński wird mit der Leitung dieser Arbeiten betraut. Der Genannte erhält seine Weisungen vom k.u.k. Kriegsarchiv in Wien und hat das geordnete und inventarisierte Material dem Kriegsarchiv abzuliefern.

Die Oberaufsicht iiber die gesamte Tätigkeit des Legionsarchivs und den hiezu kommandierten Legionspersonalspersonals obliegt dem k.u.k. Festungskommando Krakau, welches auch alle Detailanordnungen zu treffen hat.

Als Hilfskräfte sind grundsätzlich nur solche Legionunteroffiziere und Legionäre zuzuweisen, die im Superarbitrierungswege als zum Landsturmdienst ohne Waffe geeignet klassifiziert sind. Die vom Legionskommando vorgeschlagenen Hilfskräfte sind sonach dem Superarbitrierungsverfahren beim Militärkommando Krakau zu unterziehen und hat das genannte Militärkommando dem Befund dem AOK und dem k.u.k. Ministerium für Landesverteidigung zu melden. 
Die beim Legionsarchiv eingestellten Legionspersonen sind bei der Personal-sammelstelle für Polnische Legionen in Krakau in Stand zu nehmen und dort selbst überkomplett zu führen.

Der Befehl K.Nr 10 203/I vom 28 V leitendes Jahres tritt ausser Kraft.

Ergeht an das Kommando der Polnischen Legionen, an das k.u.k. Kriegsarchiv in Wien, an das k.u.k. Militärkommando in Krakau und das k.u.k. Festungskommando in Krakau und zur Kenntnis an das k.k. Ministerium für Landeverteidigung.

Fïr den Armeeoberkommandanten: Conrad General Oberst

\section{Dokument nr 22}

1916 październik 20, Cieszyn. - Pismo przedstawiciela austro-wegierskiego Ministerstwa Spraw Zagranicznych w kwaterze austro-wegierskiej Naczelnej Komendy Armii do ministra spraw zagranicznych Stefana Buriana w sprawie przeniesienia Departamentu Wojskowego NKN do Lublina.

Nach Erlassung der, mit der obenzietierten Relation gemeldeten Verfügung des Armeeoberkommandos hat die Militärsektion des Obersten Nationalkomitees beim Armee-oberkommando die Bitte gestellt, es möge ihr bis auf Weiteres noch gestattet werden, in Piotrków zu verbleiben, da abgesehen von dem in Lublin herrschenden Mangel an entsprechenden Lokalitäten für ihre Unterbringung - auch die im Zuge befindliche Reorganisation der im Hinterlande befindlichen Legionseinrichtungen und die zeitliche Abkommandierung des Legionsobersten von Sikorski an die Front diese Übersiedlung dermalen als inopportun scheinen liessen.

Diesem Ansuchen hat das Armeeoberkommando nach zustimmender Äusserung des k.u.k. Militärgeneralgouvernements in Lublin stattgegeben.

Podpis: Thurn 


\section{Dokument nr 23}

1916 październik 20, Warszawa. - Depesza barona Leopolda Andriana do austro-węgierskiego ministra spraw zagranicznych Stefana Buriana o zblizeniu $w$ niemieckiej strefie okupacyjnej Królestwa Polskiego między partiami centrum i lewicy na tle sprawy Józefa Pitsudskiego.

In den letzten Wochen ist unter der Ägide des Hofrates Rosner eine Annäherung der bisher schroff getrennten Parteien des Zentrums und der Linken in der Absicht, gegen die auf Sprengung der Legionen gerichtete Tätigkeit der militärischen Anhänger Piłsudskis zureagiren, zu Stande gekommen. Morgen begibt sich eine aus Mitgliedern beider Parteien zusamengesetzte Deputation nach Krakau, um auf das Nationalkomitee und Piłsudski im Sinne einzuwirken und auf Erhaltung der Legionen zu dringen.

Diese demarche ist umso angezeigter, als nach Nachrichten, die mir von unparteilischer, militärisscher Seite zugekommen sind, die bedenkliche, seit der Entlassung Piłsudskis entstehendene Gährung in den Legionen in der letzten Woche stark zugenommen hat und eine Krisis schon in allernächster Zeit nicht ausgeschlossen.

Brak podpisu

Maszynopis, tekst rozszyfrowanej depeszy. Haus - Hof - und Staatsarchiv, Krieg, PA I, karton 901, plik Oktober 1916, folium 229 .

\section{Dokument nr 24}

1916 październik 28, Wiedeń. - Dokument o genezie NKN przygotowany na podstawie szkicu opracowanego w austriackim Ministerstwie Spraw Wewnętrznych.

Den von den älteren Generationen ererbten Traditionen und Grundsätzen folgend, angeregt durch die militärische Tat Joseph von Piłsudskis des Gründenrs und Organisators der Schüzenverbände und militärischen, gegen Russland gerichteten Bewegung, der am 6 August 1914, gleich nach Ausbruch des Weltkrieges mit einer kühner Schar den Grenzkordon iiberschritt und unter dem ïberwältigenden Eindruck der bevorstehenden Ereignisse 
schlossen sich alle politischen Parteien Galiziens zusammen, auch die Konserwtiven und Allpolen, die der noch vor dem Kriege geschaffenen „Provisorischen Kommission der Konföderierten Unabhängigkeitsparteien", jener politischen Vertretung der polnischen militärischen Idee, in der die Unabhhängogkeitsparteien Galiziens und Polens vereint waren - ferne standen, um eine einheitliche politische Organisation, zwecks Verwirklichung der militärischen Idee zu bilden. Das so in Lemberg geschaffene Central Nationalkomitee suchte nun durch seine Führer Einvernehmen mit der „Provisorischen Kommission".

Am 9 August 1914 findet in Krakau eine Beratung der führenden politischen Persönlichkeiten statt, in der man einmütig zu dem Entschluss kam, dass die politische Führung deren Klub (aller polnischen Reichstag - und Landtagabgeordneter) zukomme. Der Polenklub - Obmann Dr Leo begibt sichdaraufhin am 9 August nach Wien, um mit den massgebenden Faktoren in Fühlung zu treten; kehrt am 14 August nach Krakau zurïck und beruft für den 15 August die parlamentarische Kommisssion des Polenklubs, die Präsidien der Landtagsklubs, unter Teilnahme der Vertreter militärischer Organisationen, ein. In der parlamentarischen Kommission werden von Dr Leo auf Grund zahlreicher Konferenzen, die er als Obmann des Polenklubs abgehalten hatte folgende Anträge gestellt. Erstens; die Schaffung einer einheitlichen öffentlichen nationalen Organisation. Zweitens; die Errichtung zweier polnischen Legionen unter polnischen Kommando im Verbande mit der k.u.k. Armee, die zum Kampfe gegen Russland auf polnischem Gebiet verwendet werden sollten. Dise Anträge wurden von der parlamentarischen Kommission angenommen, von den Vertretern aller anderen politischen Parteien (Provisorische Kommission, Zentral Nationalkomitee, und die ausserhalb dieser Organisationen stehenden Gruppen) genehmigt, worauf am nächsten Tage, 16 August 1914 die Versammlung aller polnischen Reichstag - und Landtagsabgeorneten, die Errichtung des Obersten Polnischen Nationalkomitees beschlossen und dieses als Oberste Instanz im Bereiche der militärischen, finaziellen und politischen Organisation der bewaff neten polnischen Kräfte anerkannte. Nach dem Beschluss der Landstagsversammlung hatte das Oberste Nationalkomitee aus dem Obmann des Polenklubs Dr Leo und aus 20 Mitgliedern, Vertretern aller politischen Parteien Galiziens $\mathrm{zu}$ bestehen.

In einem an die polnische Nation gerichteten Auruf von 16 August 1914 gab einerseits der parlamentarische Polenklub diesen einheitlichen Beschluss Asdruck und forderte sie auf, alle ihre Kräfte auzuraffen, um sie der Bildung der Polnischen Legionen zu widmen und sie der nun geschaffenen Organi- 
sation zur Verfïgung zu stellen, anderseits proklamierte die Versammlung der Landtagsabgeordneten eine pragmatische Erklärung ïber die Richtung und Ziele des OPNK, wobei die Schaffung und Erhaltung der gegen Russland kämpfenden Legionen näher präzisiert wurde. Diesen Aufrufen folgte eine Aufforderung an das Volk, um Herbeischaffung der zur Erhaltung der Legionen nötigen Geldmittel, die nicht fruchtlos blieb; in kurzer Zet wurden in freudiger Opferwilligkeit Millionen votiert und abgeliefert. Das Oberste Polnische Nationalkomitee zerfällt in mehrere Sektionen: die Organisztionsssektion, die Finanzsektion (mit dem Sitz in Krakau), Militärsektion (in Piotrków); in letzter Zeit wurde auch ein besonderes Fürsorgedepartement, das sich auch besonders mit Fürsorge superarbitrierter Legionäre befast, geschaffen. Bis Oktober 1914 war Präsident des OPNK Exzellenz Dr Leo, nachher bis Mai 1916 Universitätet Proffesor Dr Władysław Leopold von Jaworski, zur Zeit bekleidet diese Stelle Exzellenz von Biliński.

Odpis, maszynopis.

Haus - Hof - und Staatsarchiv, Krieg, PA I, karton 901, plik Oktober 916, str. 233-234. 